\title{
Bond between glass fibre reinforced polymer bars and high - strength
} concrete

\author{
Najia Saleh ${ }^{\mathrm{*}}$, Ashraf Ashour ${ }^{\mathrm{b}}$ and Therese Sheehan ${ }^{\mathrm{b}}$ \\ ${ }^{a}$ Civil Engineering Department, University of Omar Al-Mukhtar, Al Baida, Libya \\ b School of Engineering, University of Bradford, Bradford, BD7 1DP, UK \\ E-mails: obeidinajia@hotmail.com, \\ a.f.ashour@bradford.ac.uk,T.sheehan@bradford.ac.uk
}

\section{ABSTRACT}

In this study, bond properties of glass fibre reinforced polymer (GFRP) bars embedded in high-strength concrete (HSC) were experimentally investigated using a pull-out test. The experimental program consisted of testing 84 pull-out specimens prepared according to ACl 440.3R-12 standard. The testing of the specimens was carried out considering bar diameter (9.5, 12.7 and $15.9 \mathrm{~mm})$, embedment length $(2.5,5,7.5$ and 10 times bar diameter) and surface configuration (helical wrapping with slight sand coating (HW-SC) and sand coating (SC)) as the main parameters. Twelve pull-out specimens reinforced with $16 \mathrm{~mm}$ steel bar were also tested for comparison purposes.

Most of the specimens failed by a pull-out mode. Visual inspection of the tested specimens reinforced with GFRP (HW-SC) bars showed that the pull-out failure was due to the damage of outer bar surface, whilst the detachment of the sand coating was responsible for the bond failure of GFRP (SC) reinforced specimens. The bond stress - slip behaviour of GFRP (HW-SC) bars is different from that of GFRP (SC) bars and it was also found that GFRP (SC) bars gave a better bond performance than GFRP (HW-SC) bars. It was observed that the reduction rate of bond strength of both GFRP types with increasing the bar diameter and the embedment length was reduced in the case of high-strength concrete. Bond strength predictions obtained from ACI-440.1R, CSA-S806, CSA-S6 and 
JSCE design codes were compared with the experimental results. Overall, all design

30 guidelines were conservative in predicting bond strength of both GFRP bars in HSC and

$31 \mathrm{ACl}$ predictions were closer to the tested results than other codes.

32 Keywords: GFRP bar; high-strength concrete; pull-out; bond behaviour and design code

\section{Introduction}

34 The use of fibre reinforced polymer (FRP) re-bars as an alternative to steel reinforcement

35 has rapidly increased because of their excellent corrosion resistance, high tensile strength

to weight ratio, good non-magnetisation properties, good fatigue properties and ease of

37 handling. However, FRP reinforced concrete members behave differently to those reinforced with steel bars due to non- ductility of FRP bars, lower modulus of elasticity and bond strength which influence the performance of FRP reinforced concrete members. The mechanism of bond stress transfer between FRP bars and concrete is a fundamental

41 requirement to guarantee their successful application in concrete members. In addition,

42 the use of high-strength concretes has been recently increased owing to their higher

43 compressive and tensile strengths, better durability and higher stiffness than normal-

44 strength concretes. Many studies have been conducted to investigate the bond behaviour

45 of GFRP bars in normal-strength concrete (NSC) using a pull-out test [1-10]. However,

46 very limited research studies are available in the literature regarding the bond behaviour

47 of GFRP bars embedded in high- strength concrete using a pull-out method [5, 10-15].

48 Baena et al. [5] tested pull-out specimens reinforced with GFRP bars having various

49 surface treatments (sand coating, helical wrapping with a slight sand coating and grooves)

50 and concrete compressive strengths ( 30 and $50 \mathrm{MPa}$ ). They confirmed that different bond

51 mechanisms were observed for different surface configurations. Moreover, the effect of

52 surface treatment on bond strength was less significant for concretes with low 
compressive strengths, but it was important for concretes with high-compressive strengths

54 [5]. The influence of two types of GFRP bar (sand coating and helical wrapping with a 55 slight sand coating) on the bond performance was also investigated by Davalos et al. [11] 56 considering concrete compressive strength in the range of 57 to $63 \mathrm{MPa}$. They found that 57 sand coated GFRP bars had better bond strength than helically wrapped GFRP bars. On 58 the contrary, the results obtained by Lee et al. [12] indicated that the bond strength for the 59 helically wrapped with slightly sand coated GFRP bars was higher than that for the sand coated GFRP bars for concrete compressive strengths (25, 40 and $70 \mathrm{MPa}$ ). Hossain et

61 al. [13] tested the bond behaviour of sand-coated GFRP bars in HSC (74 MPa) with taking

62 into account two the effect of two parameters: bar diameter (15.9 and $19.1 \mathrm{~mm})$ and 63 embedment length $(3,5,7,10$ times bar diameter). Their findings showed that the 64 reduction in bond strength with increasing bar diameter was clear for each embedment 65 length. It was also observed that the decrease rate in bond strength reduced, as the 66 embedment length increased. Furthermore, the experimental investigation performed by

67 Tekle et al. [14] indicated that the increase of the embedment length of sand-coated GFRP 68 bars embedded in HSC (42 MPa) resulted in reducing in the bond strength. Lee et al. [15] investigated the effect of bar diameter (19 and $25 \mathrm{~mm}$ ) on the bond behaviour of two types of GFRP bars (sand-coated and spiral-wrapped) in high -strength concrete (40 and 60

$71 \mathrm{MPa}$ ). It was found that a reduction rate in bond strength for both GFRP types was lower 72 with increasing the bar size. Lee et al. [10] studied the influence of concrete strength on 73 the bond failure mode of helically wrapped and sand coated GFRP bars. They found that 74 bond failure occurred at the interface between concrete and outer bar surface for normal 75 strength concrete, while it occurred at the interface between outer bar surface and bar 76 core in the case of high-strength concrete. They also found that bond strength increased 
77 with increasing the concrete strength (from 25.6 to $92.4 \mathrm{MPa}$ ) and this improvement in

78 bond strength was greater in steel bars than in GFRP bars. As a result, the investigation

79 of bond properties of GFRP bars in HSC with considering the effect of bar diameter, 80 embedment length and bar surface has not been adequately covered in the literature.

81 Therefore, further research needs to be conducted.

82 According to the previous experimental investigations [1, 2, 4, 5, 16-20], it was found that

83 bond strength of GFRP bars in conventional concrete depends on several parameters,

84 such as bar diameter, embedment length, compressive concrete strength, surface

85 configuration, bar type, concrete cover, bar position and transverse reinforcement. Table 1 summarizes the parameters that influence the bond strength considered in the design

87 guidelines (ACI 440.1R [21], CSA-S806 [22], CSA-S6 [23] and JSCE [24]). The key 88 factors, namely concrete strength, bar diameter, concrete cover and bar position, are considered in all of these codes. Embedment length is only taken into account by $\mathrm{ACl}-$ 440.1R-15. The bar surface is one of the main factors which affects bond strength, however, Canadian codes only considered this influence by suggesting the bar surface

92 factor in their equations. Although each FRP type has different bond characteristics, all codes neglected the effect of fibre type on bond strength, except the Canadian codes.

94 Furthermore, confinement provided by transverse reinforcement (stirrups) along the* 95 developed and spliced reinforcing bars, that contributes in increasing bond strength, is considered by Japanese and Canadian (CSA-S6) codes, and it is ignored in other codes.

97 The performance of code equations in predicting the bond strength of GFRP (HW-SC) and GFRP (SC) re-bars embedded in high - strength concrete needs to be investigated.

99 In this paper, the results of 84 pull-out tests performed according to ACl 440.3R-12 [25] are presented with the aim of better understanding the bond properties of two common 
101 GFRP bar types (helical wrapping with a slight sand coating and sand coating) in high 102 strength concrete. The bond behaviour is analysed considering the effect of the following 103 parameters (embedment length, bar diameter and surface configuration) on bond 104 strength. The code predictions are compared with the test results for validating their 105 applicability in the case of high - strength concrete.

106 Table 1 - Main factors considered in determining bond strength by design codes

\begin{tabular}{|c|c|c|c|c|c|c|c|c|}
\hline Model & $\begin{array}{c}\text { Bar } \\
\text { diameter }\end{array}$ & $\begin{array}{c}\text { Concrete } \\
\text { strength }\end{array}$ & $\begin{array}{c}\text { Concrete } \\
\text { cover }\end{array}$ & $\begin{array}{c}\text { Bar } \\
\text { surface }\end{array}$ & $\begin{array}{c}\text { Bar } \\
\text { location }\end{array}$ & $\begin{array}{c}\text { Bonded } \\
\text { length }\end{array}$ & $\begin{array}{c}\text { Transverse } \\
\text { reinforcement }\end{array}$ & $\begin{array}{c}\text { Fibre } \\
\text { type }\end{array}$ \\
\hline JSCE 1997 & $\checkmark$ & $\checkmark$ & $\checkmark$ & $x$ & $\checkmark$ & $x$ & $\checkmark$ & $x$ \\
\hline CSA-S806-12 & $\checkmark$ & $\checkmark$ & $\checkmark$ & $\checkmark$ & $\checkmark$ & $x$ & $x$ & $\checkmark$ \\
\hline CSA-S6-14 & $\checkmark$ & $\checkmark$ & $\checkmark$ & $\checkmark$ & $\checkmark$ & $x$ & $\checkmark$ & $\checkmark$ \\
\hline ACI 440.1R-15 & $\checkmark$ & $\checkmark$ & $\checkmark$ & $x$ & $\checkmark$ & $\checkmark$ & $x$ & $x$ \\
\hline
\end{tabular}

1082 Experimental investigation

$109 \quad 2.1 \quad$ Materials

110 Pull-out cubes were constructed using ready - mixed concrete with a maximum coarse 111 aggregate size of $10 \mathrm{~mm}$. Cylinder specimens $(150 \times 300 \mathrm{~mm})$ and cube specimens $(100$ $112 \times 100 \times 100 \mathrm{~mm}$ ) were cast and cured under the same conditions as pull-out cubes. The 113 cylinders and cubes were tested immediately after testing the pull-out specimens to

114 provide the splitting tensile strength and the cube compressive strength of concrete.

115 GFRP (HW-SC), GFRP (SC) and steel bars were used in this study. Helically wrapped

116 with slightly sand coated GFRP and sand coated GFRP bars shown in Figure 1 were

117 made of continuous longitudinal fibres impregnated in vinylester resin: the minimum

118 content of continuous ECR-glass fibres was 75\% (per weight) and the maximum content

119 of vinylester resin was $25 \%$, and the content of continuous E-glass fibres $80 \%$ (per unit 120 weight) and vinylester resin $20 \%$, respectively. The tensile strength and elastic modulus

121 of GFRP and steel bars were determined according to specifications ASTM 
123 measured according to ACl 440.3R-12 [25]. The geometrical and mechanical properties

124 of GFRP and steel bars are summarized in Table 2, and the mechanical properties of

125 vinylester resin are shown in Table 3.

Table 2. Geometrical and mechanical properties of GFRP and steel bars

\begin{tabular}{c|c|c|c|c|c|c|c}
\hline Bar type & \multicolumn{2}{|c|}{ GFRP $(\mathrm{HW}-\mathrm{SC})$} & \multicolumn{3}{|c|}{ GFRP (SC) } & Steel \\
\hline Bar size & $3 \#$ & $4 \#$ & $5 \#$ & $3 \#$ & $4 \#$ & $5 \#$ & $5 \#$ \\
\hline $\begin{array}{c}\text { Nominal } \\
\text { diameter (mm) }\end{array}$ & 9.5 & 12.7 & 15.9 & 9.5 & 12.7 & 15.9 & 16 \\
\hline $\begin{array}{c}\text { Measured } \\
\text { diameter (mm) }\end{array}$ & 10.76 & 13.44 & 16.76 & 10.4 & 13.33 & 16.74 & - \\
\hline $\begin{array}{c}\text { Tensile strength } \\
(\mathrm{MPa})\end{array}$ & $\begin{array}{c}827 \\
(940.2)\end{array}$ & $\begin{array}{c}758 \\
(797)\end{array}$ & $\begin{array}{c}724 \\
(867.9)\end{array}$ & $\begin{array}{c}1227.3 \\
(1224.6)\end{array}$ & $\begin{array}{c}1375 \\
(1175.4)\end{array}$ & $\begin{array}{c}1373.7 \\
(1210.3)\end{array}$ & $\begin{array}{c}672 \\
(666)\end{array}$ \\
\hline $\begin{array}{c}\text { Ultimate strain } \\
(\%)\end{array}$ & 1.79 & 1.64 & 1.57 & 2.4 & 2.7 & 2.7 & - \\
\hline $\begin{array}{c}\text { Elastic of } \\
\text { modulus (GPa) }\end{array}$ & $\begin{array}{c}46 \\
(51.7)\end{array}$ & $\begin{array}{c}46 \\
(49.7)\end{array}$ & $\begin{array}{c}46 \\
(46.9)\end{array}$ & $\begin{array}{c}50 \\
(50.98)\end{array}$ & $\begin{array}{c}51 \\
(51.57)\end{array}$ & $\begin{array}{c}51 \\
(52.15)\end{array}$ & $\begin{array}{c}200 \\
(199)\end{array}$ \\
\hline $\begin{array}{c}\text { Yielding strength } \\
\text { (MPa) }\end{array}$ & - & - & - & - & - & - & $\begin{array}{c}582 \\
(569)\end{array}$ \\
\hline
\end{tabular}
whereas other values are provided by the manufacturer.

Table 3. Mechanical properties of vinylester resin

\begin{tabular}{l|c|c|c|c|c}
\hline Bar type & $\begin{array}{c}\text { Flexural } \\
\text { Strength } \\
(\mathrm{MPa})\end{array}$ & $\begin{array}{c}\text { Flexural } \\
\text { Modulus } \\
(\mathrm{MPa})\end{array}$ & $\begin{array}{c}\text { Tensile } \\
\text { Strength } \\
(\mathrm{MPa})\end{array}$ & $\begin{array}{c}\text { Tensile } \\
\text { Elongation } \\
(\%)\end{array}$ & $\begin{array}{c}\text { Tensile } \\
\text { Modulus } \\
(\mathrm{MPa})\end{array}$ \\
\hline GFRP (HW-SC) & 144 & 3500 & 84 & 4.2 & 3400 \\
\hline GFRP (SC) & 156 & 3172 & 90 & 4.2 & 3586 \\
\hline
\end{tabular}

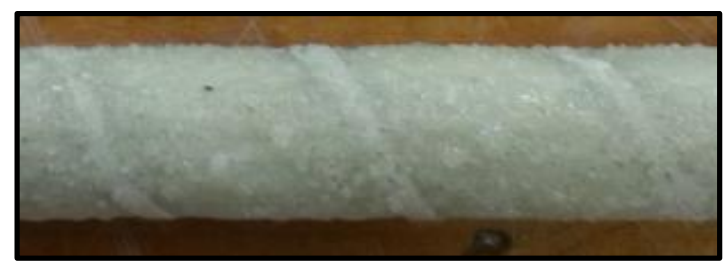

(a) Helically wrapped with sand coated surface (type A) 
154 three layers and each layer was vibrated using a poker vibrator. After casting, all

156 unhardened concrete until demoulding. After one week, the specimens were demoulded, 157 marked, covered with a polythene sheet and stored in a temperature-controlled laboratory 158 until testing.

(b) Sand coated surface (type B)

\section{Figure 1. Surface configurations of GFRP re-bars}

\section{$2.2 \quad$ Test specimens}

Seventy-two GFRP and twelve steel reinforced cubes were tested. The parameters investigated were bar diameter $(9.5,12.7$ and $15.9 \mathrm{~mm}$ for GFRP and $16 \mathrm{~mm}$ for steel) and embedment length (2.5, 5, 7.5 and 10 times bar diameter). The geometrical details of the pull-out cubes are given in Figure 2. The un-bonded length was covered by a PVC tube to prevent contact between the bar and the concrete. The concrete mix (C1) was used to cast cubes reinforced with GFRP (type A) and steel reinforced concrete cubes having embedment lengths $2.5 \mathrm{db}$ and $5 \mathrm{db}$. Specimens reinforced with GFRP (type B) and those reinforced with steel bars having embedment lengths $7.5 \mathrm{db}$ and $10 \mathrm{db}$ were cast using the second batch (C2). Before casting, the inner sides of the moulds were covered by a thin film of oil to allow demoulding of the specimens. The concrete was placed in specimens were covered with a polythene sheet to prevent evaporation of water from the 


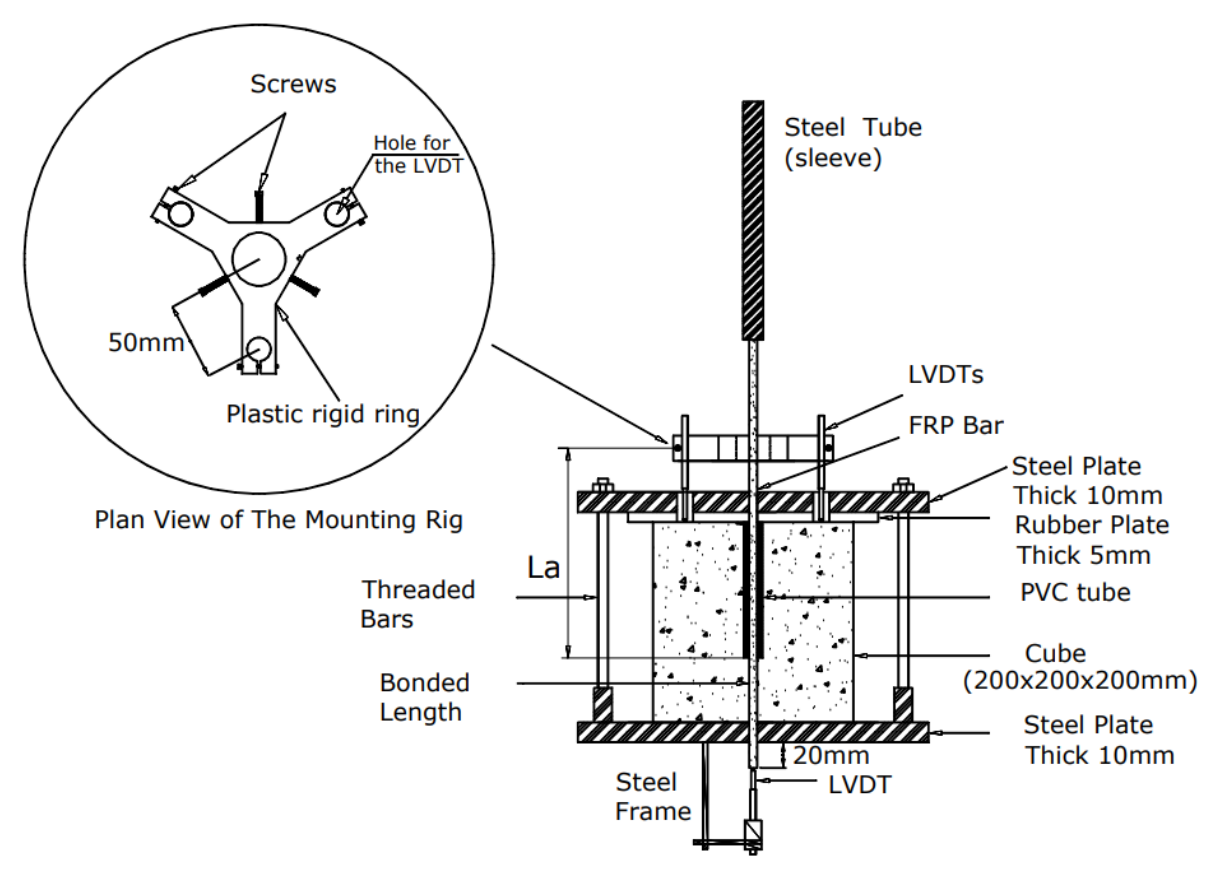

Figure 2. Pull-out test arrangement

\section{$161 \quad 2.3 \quad$ Experimental set-up}

162 The pull-out test set-up is shown in Figure 3. The specimen was placed in a specially 163 made steel frame that was positioned in the testing machine. Three linear variable 164 displacement transducers (LVDTs) were connected to the bar by a plastic rigid rig and 165 touched the top surface of the specimen to measure the loaded end slip. Only one LVDT 166 was attached to a small steel frame which was fixed to the below surface of the concrete 167 cube to measure the free end slip. Small irregularities at the top surface of the cube might 168 result in accidental bending of the bar during loading or movements caused by local 169 crushing. Therefore, a 5-mm-thick rubber plate was introduced to secure the contact 170 between the top surface of the concrete block and the steel bearing plate. The tensile load 171 was applied directly to the bar using a testing machine of $500 \mathrm{kN}$ capacity. The loading 172 rate was changed for each $15 \mathrm{~mm}$ of head movement of the machine to be $0.02,0.05$ and $1730.1 \mathrm{~mm} / \mathrm{sec}$, respectively. The reason for increasing the loading rate was to accelerate 
174 the test after the occurrence of pull-out failure. The displacement-control mode was 175 selected to record the post-peak curve. Applied load and LVDT readings were 176 automatically recorded using the data logging system.

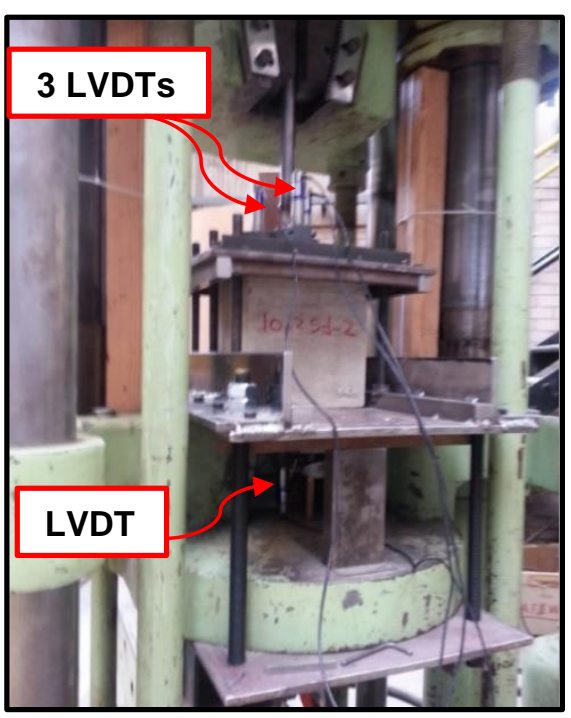

Figure 3. Pull-out test set-up

\section{$1793 \quad$ Test results and discussion}

180 Three identical specimens for each configuration were tested. The bond stress - slip 181 relationships were developed and plotted using measured data. The bond stress is 182 defined by equation 1.

$$
\tau=\frac{F}{\pi d_{b} l_{e}}
$$

where $\tau$ is the bond stress $\left(\mathrm{N} / \mathrm{mm}^{2}\right) ; F$ is the applied tensile load $(\mathrm{N})$; $\mathrm{d}_{\mathrm{b}}$ is the bar diameter

$186(\mathrm{~mm})$ and $\mathrm{l}_{\mathrm{e}}$ is the embedment length $(\mathrm{mm})$. As the three LVDTs readings at the loaded

187 end of the bar covered both the loaded end slip and the elastic elongation of the bar above

188 the embedment length $\left(L_{a}\right)$ (see Figure 2), therefore, the loaded end slip $\left(s_{l e}\right)$ is calculated

189 by subtracting the LVDT measurement $\left(s_{+o t a l}\right)$ from the bar extension $\left(s_{e}\right)$ as illustrated in 190 equations 2 and 3 : 


$$
s_{l e}=s_{\text {total }}-s_{e}
$$

$$
s_{e}=\frac{F \cdot L_{a}}{A_{b} \cdot E_{f r p}}
$$

193 where $A_{b}$ is the cross-sectional area of bar $\left(\mathrm{mm}^{2}\right), L_{a}$ is the length from the LVDTs support 194 point to the top surface of the bonded bar $(\mathrm{mm})$ (see Figure 2) and $E_{f r p}$ is the elastic 195 modulus of the bar (MPa). The displacement at the unloaded end of bar was directly 196 obtained from the slip measurement of the bottom LVDT. The maximum applied load $197\left(F_{\max }\right)$, the maximum bond strength $\left(\tau_{\max }\right)$ with the corresponding loaded end slip $\left(\mathrm{s}_{\mathrm{le}}\right)$ and 198 unloaded end slip $\left(\mathrm{S}_{\mathrm{ul}}\right)$, failure mode, the average compressive strength of four concrete 199 cubes $\left(\mathrm{f}_{\mathrm{cu}}\right)$ and average splitting tensile strength of three concrete cylinders $\left(\mathrm{f}_{\mathrm{t}}\right)$ are 200 presented for specimens reinforced with type $A$ and type $B$ in Tables $\underline{4}$ and 5 , respectively. 201 The mean values of bond strength $\left(\tau_{\text {avg }}\right)$ and the corresponding loaded end and free end 202 slips $\left(s_{l e, m}\right.$ and $\left.s_{u l, m}\right)$ (obtained as an average of the results of three identical specimens) 203 are also reported. The cube compressive strength of concrete $\mathrm{C} 1$ was in the range of 20497.38 to $102.36 \mathrm{MPa}$ with an average of $100.17 \mathrm{MPa}$ and a coefficient of variation (COV) 205 of $2.4 \%$. As for concrete $\mathrm{C} 2$, it changed from 77.47 to $83.07 \mathrm{MPa}$ with an average of 79.24 $206 \mathrm{MPa}$ and a COV of $2.9 \%$. The average splitting tensile strength of concrete $\mathrm{C} 1$ and $\mathrm{C} 2$ 207 obtained from testing three cylinders varied from 4.13 MPa to 4.71 MPa with an average 208 of $4.34 \mathrm{MPa}$ and a COV of $7.3 \%$ and changed from 3.24 MPa to 3.67 MPa with an average 209 of $3.46 \mathrm{MPa}$ and a COV of $6.2 \%$, respectively. A small difference was observed among 210 the bond strengths of the three identical cubes because of the non-homogenous nature 211 of conventional concrete. The definition of specimen notation is as follows: the first letter 212 denotes the bar type (A for GFRP (HW-SC), B for GFRP (SC) and C for steel); the first 
213 number indicates the bar diameter; the second one denotes the embedment length and

214 the last number refers to the specimen number.

215 Table 4. Experimental results of pull-out cubes reinforced with GFRP (HW-SC) bars in concrete C1

\begin{tabular}{|c|c|c|c|c|c|c|c|c|c|c|}
\hline $\begin{array}{l}\text { Specimen } \\
\text { label }\end{array}$ & $\begin{array}{c}f_{c u} \\
(\mathrm{MPa})\end{array}$ & $\begin{array}{c}f_{t} \\
(\mathrm{MPa})\end{array}$ & $\begin{array}{l}F_{\max } \\
(\mathbf{k N})\end{array}$ & $\begin{array}{c}\tau_{\max } \\
(\mathrm{MPa})\end{array}$ & $\begin{array}{c}S_{\mathrm{ul}} \\
(\mathrm{mm})\end{array}$ & $\begin{array}{c}S_{\mathrm{le}} \\
(\mathrm{mm})\end{array}$ & $\begin{array}{c}\tau_{a v g} \\
(\mathrm{MPa})\end{array}$ & $\begin{array}{c}S_{u l, m} \\
(\mathrm{~mm})\end{array}$ & $\begin{array}{c}S_{l e, m} \\
(\mathrm{~mm})\end{array}$ & $\begin{array}{c}\text { Failure } \\
\text { Mode }\end{array}$ \\
\hline$A-9.5-2.5 d-1$ & 97.38 & 4.13 & 14.95 & 21.09 & 0.434 & 0.531 & \multirow{3}{*}{20.55} & \multirow{3}{*}{0.306} & \multirow{3}{*}{0.416} & $\mathrm{PO}$ \\
\hline$A-9.5-2.5 d-2$ & 97.38 & 4.13 & 14.11 & 19.9 & 0.193 & 0.228 & & & & $\mathrm{PO}$ \\
\hline A-9.5-2.5d-3 & 97.38 & 4.13 & 14.64 & 20.66 & 0.291 & 0.490 & & & & $\mathrm{PO}$ \\
\hline$A-9.5-5 d-1$ & 97.38 & 4.13 & 28.47 & 20.08 & 0.124 & 0.378 & \multirow{3}{*}{20.08} & \multirow{3}{*}{0.211} & \multirow{3}{*}{0.448} & $\mathrm{PO}$ \\
\hline$A-9.5-5 d-2$ & 97.38 & 4.13 & 27.83 & 19.63 & 0.391 & 0.659 & & & & $\mathrm{PO}$ \\
\hline$A-9.5-5 d-3$ & 97.38 & 4.13 & 29.11 & 20.53 & 0.118 & 0.309 & & & & $\mathrm{PO}$ \\
\hline A-9.5-7.5d-1 & 97.38 & 4.13 & \multicolumn{8}{|c|}{ The testing machine suddenly stopped before debonding failure } \\
\hline A-9.5-7.5d-2 & 97.38 & 4.13 & 41.98 & 19.73 & 0.104 & 1.127 & \multirow{2}{*}{19.76} & \multirow{2}{*}{0.106} & \multirow{2}{*}{0.898} & $\mathrm{PO}$ \\
\hline A-9.5-7.5d-3 & 97.38 & 4.13 & 42.1 & 19.79 & 0.108 & 0.67 & & & & $\mathrm{PO}$ \\
\hline A-9.5-10d-1 & 97.38 & 4.13 & 55.7 & 19.65 & 0.411 & 1.486 & \multirow{3}{*}{19.27} & \multirow{3}{*}{0.621} & \multirow{3}{*}{1.620} & $\mathrm{PO}$ \\
\hline A-9.5-10d-2 & 97.38 & 4.13 & 55.3 & 19.49 & 0.659 & 1.477 & & & & $\mathrm{PO}$ \\
\hline A-9.5-10d-3 & 97.38 & 4.13 & 53 & 18.68 & 0.793 & 1.897 & & & & $\mathrm{PO}$ \\
\hline$A-12.7-2.5 d-1$ & 97.72 & 4.19 & 28.26 & 22.3 & 0.407 & 0.436 & \multirow{3}{*}{19.79} & \multirow{3}{*}{0.486} & \multirow{3}{*}{0.547} & $\mathrm{PO}$ \\
\hline$A-12.7-2.5 d-2$ & 97.72 & 4.19 & 23.01 & 18.16 & 0.75 & 0.80 & & & & $\mathrm{PO}$ \\
\hline$A-12.7-2.5 d-3$ & 97.72 & 4.19 & 23.95 & 18.90 & 0.301 & 0.405 & & & & $\mathrm{PO}$ \\
\hline$A-12.7-5 d-1$ & 97.72 & 4.19 & 41.15 & 16.24 & 6.94 & 7.03 & \multirow{3}{*}{16.13} & \multirow{3}{*}{$z^{*}$} & \multirow{3}{*}{$z^{*}$} & $\mathrm{PO}$ \\
\hline$A-12.7-5 d-2$ & 97.72 & 4.19 & 40.61 & 16.02 & 5.99 & 6.151 & & & & $\mathrm{PO}$ \\
\hline$A-12.7-5 d-3$ & 97.72 & 4.19 & 40.86 & 16.13 & 6.387 & 6.446 & & & & $\mathrm{PO}$ \\
\hline$A-12.7-7.5 d-1$ & 97.72 & 4.19 & 61.60 & 16.20 & 0.506 & 1.338 & \multirow{3}{*}{16.71} & \multirow{3}{*}{0.679} & \multirow{3}{*}{1.215} & $\mathrm{PO}$ \\
\hline$A-12.7-7.5 d-2$ & 97.72 & 4.19 & 59.04 & 15.53 & 0.736 & 1.139 & & & & $\mathrm{PO}$ \\
\hline$A-12.7-7.5 d-3$ & 97.72 & 4.19 & 69.90 & 18.39 & 0.797 & 1.169 & & & & $\mathrm{PO}$ \\
\hline A-12.7-10d-1 & 97.72 & 4.19 & 77.47 & 15.28 & 0.468 & 1.545 & \multirow{3}{*}{16.05} & \multirow{3}{*}{0.728} & \multirow{3}{*}{1.612} & $\mathrm{PO}$ \\
\hline$A-12.7-10 d-2$ & 97.72 & 4.19 & 79.94 & 15.77 & 0.744 & 1.798 & & & & $\mathrm{PO}$ \\
\hline$A-12.7-10 d-3$ & 97.72 & 4.19 & 86.70 & 17.10 & 0.974 & 1.493 & & & & $\mathrm{PO}$ \\
\hline
\end{tabular}




\begin{tabular}{|c|c|c|c|c|c|c|c|c|c|c|}
\hline$A-15.9-2.5 d-1$ & 101.68 & 4.71 & 42.13 & 21.21 & 0.458 & 0.634 & \multirow{3}{*}{19.42} & \multirow{3}{*}{0.363} & \multirow{3}{*}{0.496} & $\mathrm{PO}$ \\
\hline$A-15.9-2.5 d-2$ & 101.68 & 4.71 & 38.55 & 19.42 & 0.330 & 0.414 & & & & $\mathrm{PO}$ \\
\hline$A-15.9-2.5 d-3$ & 101.68 & 4.71 & 35 & 17.62 & 0.302 & 0.440 & & & & $\mathrm{PO}$ \\
\hline$A-15.9-5 d-1$ & 101.68 & 4.71 & 70.65 & 17.78 & 0.388 & 1.049 & \multirow{3}{*}{18.70} & \multirow{3}{*}{0.60} & \multirow{3}{*}{1.097} & $\mathrm{PO}$ \\
\hline$A-15.9-5 d-2$ & 101.68 & 4.71 & 79.04 & 19.90 & 0.826 & 1.111 & & & & $\mathrm{PO}$ \\
\hline$A-15.9-5 d-3$ & 101.68 & 4.71 & 73.20 & 18.42 & 0.586 & 1.131 & & & & $\mathrm{PO}$ \\
\hline$A-15.9-7.5 d-1$ & 102.36 & 4.71 & 97.21 & 16.32 & 0.439 & 1.170 & \multirow{3}{*}{16.32} & \multirow{3}{*}{0.533} & \multirow{3}{*}{1.208} & $\mathrm{PO}$ \\
\hline$A-15.9-7.5 d-2$ & 102.36 & 4.71 & 98.51 & 16.53 & 0.858 & 1.234 & & & & $\mathrm{PO}$ \\
\hline$A-15.9-7.5 d-3$ & 102.36 & 4.71 & 96.02 & 16.11 & 0.304 & 1.220 & & & & $\mathrm{PO}$ \\
\hline$A-15.9-10 d-1$ & 102.36 & 4.71 & 115.5 & 14.55 & 0.410 & 1.561 & \multirow{3}{*}{14.82} & \multirow{3}{*}{0.660} & \multirow{3}{*}{1.628} & $\mathrm{PO}$ \\
\hline$A-15.9-10 d-2$ & 102.36 & 4.71 & 116.9 & 14.72 & 0.656 & 1.619 & & & & $\mathrm{PO}$ \\
\hline A-15.9-10d-3 & 102.36 & 4.71 & 120.7 & 15.20 & 0.915 & 1.706 & & & & $\mathrm{PO}$ \\
\hline$C-16-2.5 d-1$ & 97.38 & 4.13 & 76.2 & 37.88 & 0.939 & 1.481 & \multirow{2}{*}{38} & \multirow{2}{*}{0.766} & \multirow{2}{*}{1.444} & $\mathrm{PO}$ \\
\hline$C-16-2.5 d-2$ & 97.38 & 4.13 & 76.85 & 38.21 & 0.593 & 1.408 & & & & $\mathrm{PO}$ \\
\hline$C-16-5 d-1$ & 101.7 & 4.71 & 120.5 & 29.94 & - & 1.924 & \multirow{3}{*}{27.56} & \multirow{3}{*}{1.534} & \multirow{3}{*}{1.864} & $\mathrm{PO}$ \\
\hline C-16-5d-2 & 101.7 & 4.71 & 101.4 & 25.20 & 1.534 & 1.804 & & & & $\mathrm{PO}$ \\
\hline$C-16-5 d-3$ & 101.7 & 4.71 & 110.8 & 27.55 & - & 1.864 & & & & $\mathrm{PO}$ \\
\hline
\end{tabular}

216 Note: * indicates specimens exhibited an almost yield plateau until full slip without a clear peak bond

217 strength.

218 Table 5. Experimental results of pull-out cubes reinforced with GFRP (SC) bars in concrete C2

\begin{tabular}{|c|c|c|c|c|c|c|c|c|c|c|}
\hline $\begin{array}{l}\text { Specimen } \\
\text { label }\end{array}$ & $\begin{array}{c}f_{c u} \\
(\mathrm{MPa})\end{array}$ & $\begin{array}{c}f_{t} \\
(\mathrm{MPa})\end{array}$ & $\begin{array}{l}F_{\max } \\
(\mathbf{k N})\end{array}$ & $\begin{array}{c}\tau_{\max } \\
(\mathrm{MPa})\end{array}$ & $\begin{array}{c}S_{u l} \\
(\mathrm{~mm})\end{array}$ & $\begin{array}{c}S_{\mathrm{le}} \\
(\mathrm{mm})\end{array}$ & $\begin{array}{c}\tau_{\text {avg }} \\
(\mathrm{MPa})\end{array}$ & $\begin{array}{c}S_{u l, m} \\
(\mathrm{~mm})\end{array}$ & $\begin{array}{l}S_{l e, m} \\
(\mathrm{~mm})\end{array}$ & $\begin{array}{r}\text { Failure } \\
\text { Mode }\end{array}$ \\
\hline B-9.5-2.5d-1 & 83.07 & 3.67 & 20.49 & 28.91 & 0.203 & 0.272 & \multirow{3}{*}{28.91} & \multirow{3}{*}{0.237} & \multirow{3}{*}{0.287} & $\mathrm{PO}$ \\
\hline B-9.5-2.5d-2 & 83.07 & 3.67 & 21.55 & 30.38 & 0.193 & 0.225 & & & & $\mathrm{PO}$ \\
\hline B-9.5-2.5d-3 & 83.07 & 3.67 & 19.45 & 27.44 & 0.315 & 0.365 & & & & $\mathrm{PO}$ \\
\hline B-9.5-5d-1 & 77.68 & 3.24 & 37.20 & 26.23 & 0.138 & 0.581 & \multirow{3}{*}{25.51} & \multirow{3}{*}{0.139} & \multirow{3}{*}{0.570} & $\mathrm{PO}$ \\
\hline$B-9.5-5 d-2$ & 77.68 & 3.24 & 37.57 & 26.49 & 0.200 & 0.776 & & & & $\mathrm{PO}$ \\
\hline$B-9.5-5 d-3$ & 77.68 & 3.24 & 33.78 & 23.82 & 0.081 & 0.377 & & & & $\mathrm{PO}$ \\
\hline B-9.5-7.5d-1 & 77.68 & 3.24 & 49.96 & 23.48 & 0.203 & 0.695 & \multirow{2}{*}{22.15} & \multirow{2}{*}{0.187} & \multirow{2}{*}{0.716} & PO \\
\hline B-9.5-7.5d-2 & 77.68 & 3.24 & 45.94 & 21.59 & 0.213 & 0.726 & & & & $\mathrm{PO}$ \\
\hline
\end{tabular}




\begin{tabular}{|c|c|c|c|c|c|c|c|c|c|c|}
\hline B-9.5-7.5d-3 & 77.68 & 3.24 & 45.50 & 21.39 & 0.145 & 0.729 & & & & $\mathrm{PO}$ \\
\hline B-9.5-10d-1 & 77.68 & 3.24 & 54 & 19.05 & 0.191 & 0.971 & \multirow{3}{*}{19.05} & \multirow{3}{*}{0.191} & \multirow{3}{*}{1.079} & $\mathrm{PO}$ \\
\hline B-9.5-10d-2 & 77.68 & 3.24 & 54.79 & 19.31 & 0.219 & 1.106 & & & & $\mathrm{PO}$ \\
\hline B-9.5-10d-3 & 77.68 & 3.24 & 53.30 & 18.79 & 0.165 & 1.160 & & & & $\mathrm{PO}$ \\
\hline B-12.7-2.5d-1 & 79.72 & 3.48 & 37.34 & 29.48 & 0.124 & 0.213 & \multirow{3}{*}{28.26} & \multirow{3}{*}{0.145} & \multirow{3}{*}{0.230} & PO \\
\hline$B-12.7-2.5 d-2$ & 79.72 & 3.48 & 34.27 & 27.04 & 0.170 & 0.286 & & & & $\mathrm{PO}$ \\
\hline B-12.7-2.5d-3 & 79.72 & 3.48 & 35.81 & 28.26 & 0.142 & 0.193 & & & & $\mathrm{PO}$ \\
\hline B-12.7-5d-1 & 79.72 & 3.48 & 57.36 & 22.63 & 0.216 & 0.504 & \multirow{3}{*}{23.21} & \multirow{3}{*}{0.261} & \multirow{3}{*}{0.523} & $\mathrm{PO}$ \\
\hline B-12.7-5d-2 & 79.72 & 3.48 & 60.96 & 24.05 & 0.232 & 0.548 & & & & PO \\
\hline B-12.7-5d-3 & 79.72 & 3.48 & 58.14 & 22.94 & 0.336 & 0.518 & & & & $\mathrm{PO}$ \\
\hline B-12.7-7.5d-1 & 77.47 & 3.24 & 75.36 & 19.83 & 0.218 & 0.827 & \multirow{3}{*}{19.83} & \multirow{3}{*}{0.232} & \multirow{3}{*}{0.858} & $\mathrm{PO}$ \\
\hline B-12.7-7.5d-2 & 77.47 & 3.24 & 77.44 & 20.37 & 0.206 & 0.879 & & & & PO \\
\hline B-12.7-7.5d-3 & 77.47 & 3.24 & 73.35 & 19.29 & 0.273 & 0.869 & & & & $\mathrm{PO}$ \\
\hline B-12.7-10d-1 & 77.47 & 3.24 & 92.53 & 18.25 & 0.223 & 1.418 & \multirow{3}{*}{18.18} & \multirow{3}{*}{0.166} & \multirow{3}{*}{1.345} & PO \\
\hline B-12.7-10d-2 & 77.47 & 3.24 & 92.12 & 18.18 & 0.092 & 1.297 & & & & PO \\
\hline B-12.7-10d-3 & 77.47 & 3.24 & 91.77 & 18.10 & 0.185 & 1.322 & & & & PO \\
\hline B-15.9-2.5d-1 & 77.47 & 3.24 & 55.15 & 27.77 & 0.250 & 0.406 & \multirow{3}{*}{27.77} & \multirow{3}{*}{0.250} & \multirow{3}{*}{0.369} & $\mathrm{PO}$ \\
\hline B-15.9-2.5d-2 & 77.47 & 3.24 & 57.69 & 29.04 & 0.210 & 0.320 & & & & $\mathrm{PO}$ \\
\hline B-15.9-2.5d-3 & 77.47 & 3.24 & 52.61 & 26.5 & 0.291 & 0.381 & & & & $\mathrm{PO}$ \\
\hline B-15.9-5d-1 & 77.47 & 3.24 & 90.23 & 22.71 & 0.199 & 0.596 & \multirow{3}{*}{21.52} & \multirow{3}{*}{0.179} & \multirow{3}{*}{0.595} & $\mathrm{PO}$ \\
\hline B-15.9-5d-2 & 77.47 & 3.24 & 84.63 & 21.30 & 0.161 & 0.583 & & & & $\mathrm{PO}$ \\
\hline B-15.9-5d-3 & 77.47 & 3.24 & 81.60 & 20.54 & 0.178 & 0.607 & & & & $\mathrm{PO}$ \\
\hline B-15.9-7.5d-1 & 77.47 & 3.24 & 125.6 & 21.08 & 0.063 & 1.025 & \multirow{3}{*}{19.23} & \multirow{3}{*}{0.332} & \multirow{3}{*}{1.027} & $\mathrm{PO}$ \\
\hline B-15.9-7.5d-2 & 77.47 & 3.24 & 103.5 & 17.38 & 0.763 & 1.212 & & & & PO \\
\hline B-15.9-7.5d-3 & 77.47 & 3.24 & 114.5 & 19.23 & 0.170 & 0.845 & & & & $\mathrm{PO}$ \\
\hline B-15.9-10d-1 & 77.47 & 3.24 & 150.4 & 18.93 & 0.441 & 1.766 & \multirow{3}{*}{19.41} & \multirow{3}{*}{0.441} & \multirow{3}{*}{1.763} & $\mathrm{PO}$ \\
\hline B-15.9-10d-2 & 77.47 & 3.24 & 156.2 & 19.67 & - & 1.832 & & & & $\mathrm{PO}$ \\
\hline B-15.9-10d-3 & 77.47 & 3.24 & 155.9 & 19.63 & - & 1.693 & & & & PO \\
\hline
\end{tabular}




\begin{tabular}{|c|c|c|c|c|c|c|c|c|c|c|}
\hline$C-16-7.5 d-1$ & 78.28 & 3.48 & 142 & $>23.54$ & 0.281 & 0.646 & & & & Y \\
\hline C-16-7.5d-2 & 78.28 & 3.48 & 142.7 & $>23.65$ & 0.252 & 0.615 & $>23.1$ & 0.199 & 0.587 & Y \\
\hline C-16-7.5d-3 & 78.28 & 3.48 & 134 & $>22.21$ & 0.066 & 0.502 & & & & $Y$ \\
\hline C-16-10d-1 & 78.28 & 3.48 & 133.9 & $>16.64$ & 0.495 & 0.758 & & & & $Y$ \\
\hline C-16-10d-2 & 78.28 & 3.48 & 131.3 & $>16.33$ & 0.541 & 0.607 & $>16.60$ & 0.446 & 0.740 & $Y$ \\
\hline C-16-10d-3 & 78.28 & 3.48 & 135.4 & $>16.84$ & 0.304 & 0.857 & & & & $Y$ \\
\hline
\end{tabular}

219 Note: $\mathrm{PO}=$ Pull-out failure; $\mathrm{SP}=$ Splitting failure and $\mathrm{Y}=$ Bar yielding

$220(-)=$ Not measured (LVDT stopped)

\subsection{Bond stress - slip relationship}

223 The response of bond stress - loaded and unloaded end slips for each specimen is

224 illustrated in Figures 4 to 6 for cubes reinforced with GFRP (type A) bars and Figures 7 to

2259 for GFRP (type B) reinforced cubes. The bond stress - slip curves for cubes reinforced

226 with steel bars are also plotted in Figure 10. The bond stress - slip relationships are

227 presented according to bar diameter, embedment length, surface characteristics and bar

228 type to observe the influence of these main parameters on the bond behaviour in case of

229 high-strength concrete.

230 The general trend of bond stress - slip curve for GFRP (HW-SC) bars is similar to that 231 obtained by Lee et al. [12], Baena et al. [5], Davalos et al. [11], Okelo and Yuan [2] and 232 Vint and Sheikh [28] from testing GFRP (HW-SC) reinforced specimens. In addition, the 233 bond stress - slip behaviour for GFRP (SC) bars is similar to that reported by Vint and 234 Sheikh [28], Baena et al. [5], Davalos et al. [11], Hossain et al. [13], El Refai et al. [7], Lee 235 et al. [12], Antonietta Aiello et al. [29] and Arias et al. [30] from testing GFRP (SC) 236 reinforced specimens.

237 The general behaviour of the bond stress - slip relationship is described by a high initial 238 increase in bond stress without a significant slip in both GFRP types and steel bars due 
239 to good chemical adhesion between the bar surface and the concrete. This stage 240 describes the initial stiffness. After the chemical adhesion resistance is lost, bond stress

241 continues to increase with increasing the applied load until the peak point, but the amount

242 of the slip increase is small. At this stage, bearing (undulations) and friction resistances

243 control to prevent de-bonding in GFRP (HW-SC) reinforced specimens. However, friction

244 resistance only dominates in specimens reinforced with GFRP (SC) bars and the 245 mechanical interlock only controls to resist the pull-out force in steel reinforced specimens.

246 In the descending stage (after bond failure), the bond stress reduces with increasing the

247 slip in both GFRP types, but the shape of the softening curve changes with differing 248 surface configuration. In specimens reinforced with helically wrapped and slightly sand 249 coated GFRP bars, bond stress degraded gradually with increasing the loaded and 250 unloaded end slips. It was noted that the reduction rate in residual bond stresses 251 increases with decreasing bar diameter as rib spacing of smaller diameter bars is larger 252 than that of higher diameter bars (rib spacings $=25,23$ and $20 \mathrm{~mm}$ with a constant rib 253 height for bar diameters $=9.5,12.7$ and $15.9 \mathrm{~mm}$, respectively), indicating that residual 254 bond stresses depend on bar size. As for GFRP (type B) reinforced specimens, the bond 255 stress reduced suddenly to be almost zero with a strong slip accompanied with a loud 256 bang (relative brittle failure and significant energy release) due to detaching of the sand 257 coated layer. No data was recorded during that short moment. Then, bond stress started 258 to increase again up to a certain level, followed by an increase in the slip owing to the 259 remaining frictional resistance. The residual bond stresses produced in GFRP (SC) 260 reinforced specimens are lower than those produced in GFRP (HW-SC) reinforced 261 specimens due to loss of frictional resistance, when the sand coating layer was entirely 262 stripped, leading to a smooth surface. For steel reinforced cubes that failed in a pull-out 
263 mode, the post-peak bond stresses reduced gradually similar to GFRP (HW-SC) bars, 264 however, the reduction was faster than the reduction in GFRP (HW-SC) reinforced 265 specimens owing to lower frictional resistance. The bond stress - slip behaviour of 266 specimens A-12.7-5d was different from other specimens reinforced with GFRP (HW-SC) 267 bars as specimens exhibited an almost yield plateau until full slip without a clear peak 268 bond strength, but similar to that obtained by Baena et al. [5] and Lee et al. [12] from 269 testing GFRP (HW-SC) reinforced specimens. This might be attributed to the wedging

270 action resulting from the crushed concrete sticking to the front of the ribs. From the bond 271 stress - slip curves (Figures 4 to 10), Tables 4 and 5 , it can be noted that the loaded end 272 slip is higher than the unloaded end slip at the same pull-out load, indicating that the high 273 bond stress at the loaded end reduces gradually towards the unloaded end (non-linear 274 distribution).

275 The bond strength of GFRP (SC) bars is higher than that of GFRP (HW-SC) bars, but the 276 corresponding slip for GFRP (SC) bars is smaller than that for GFRP (HW-SC) bars, 277 indicating that bond properties of sand coated surfaces are better than those of the 278 helically wrapped surfaces, and the amount of slip is influenced by the bar surface. The 279 effect of surface configuration on the slip was confirmed by Lee et al. [12] and Pepe et al. 280 [31]. In addition, it is noticed that the loaded end slip corresponding to the maximum bond 281 stress increases with increasing embedment length for the same bar diameter in both 282 GFRP types and this was also reported by Pepe et al. [31] and Tekle et al. [14]. Steel 283 reinforced cubes having embedment lengths of 7.5 and 10 times the bar diameter were 284 failed by yielding as shown in Figure 10, because the pullout force exceeded the force 285 causing the bar fracture. 


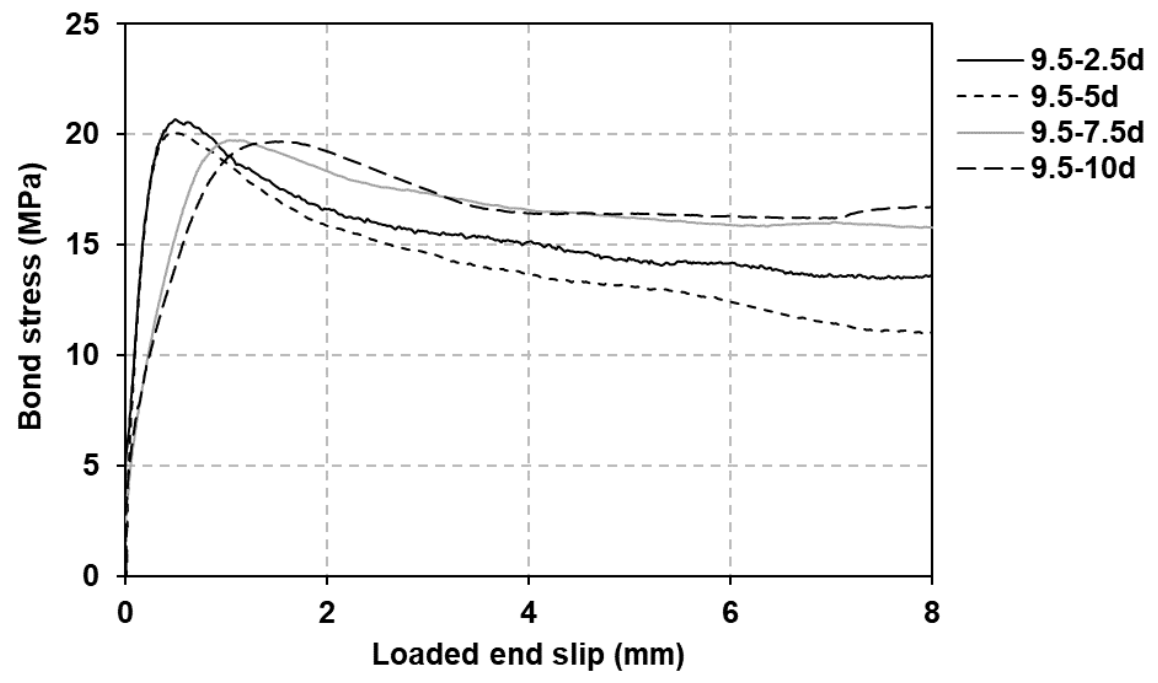

(a)

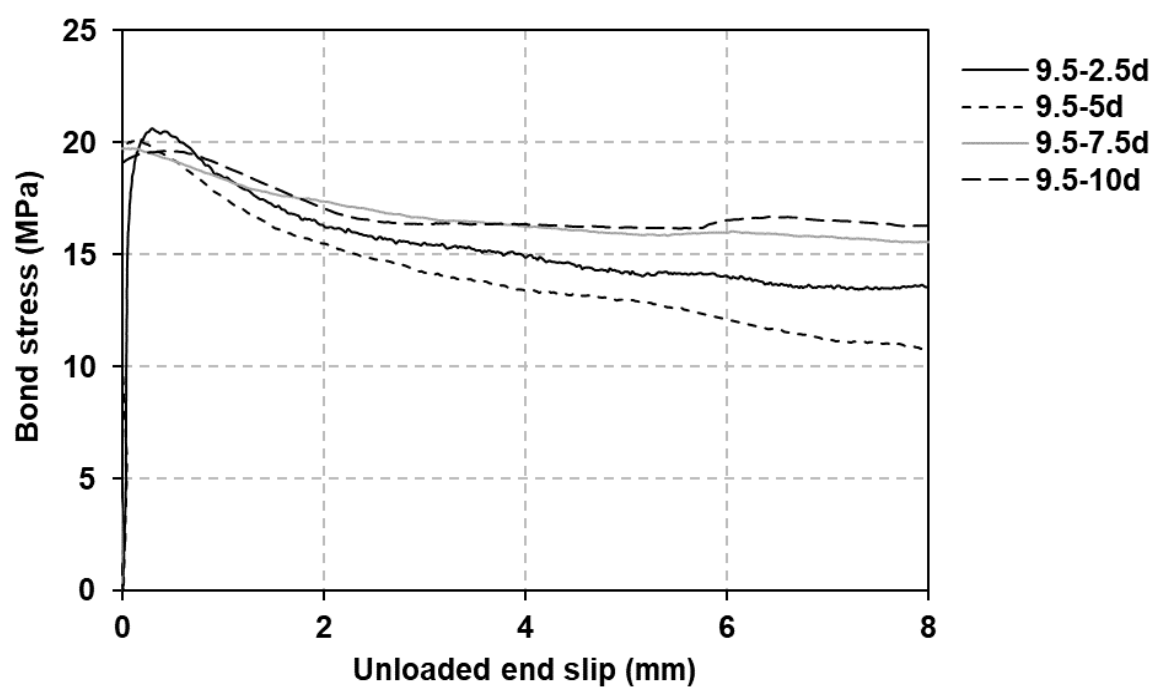

Figure 4. Bond stress - slip relationship for $9.5 \mathrm{~mm}$ GFRP (type A) reinforced cubes: (a) loaded and 292 (b) unloaded end slips 


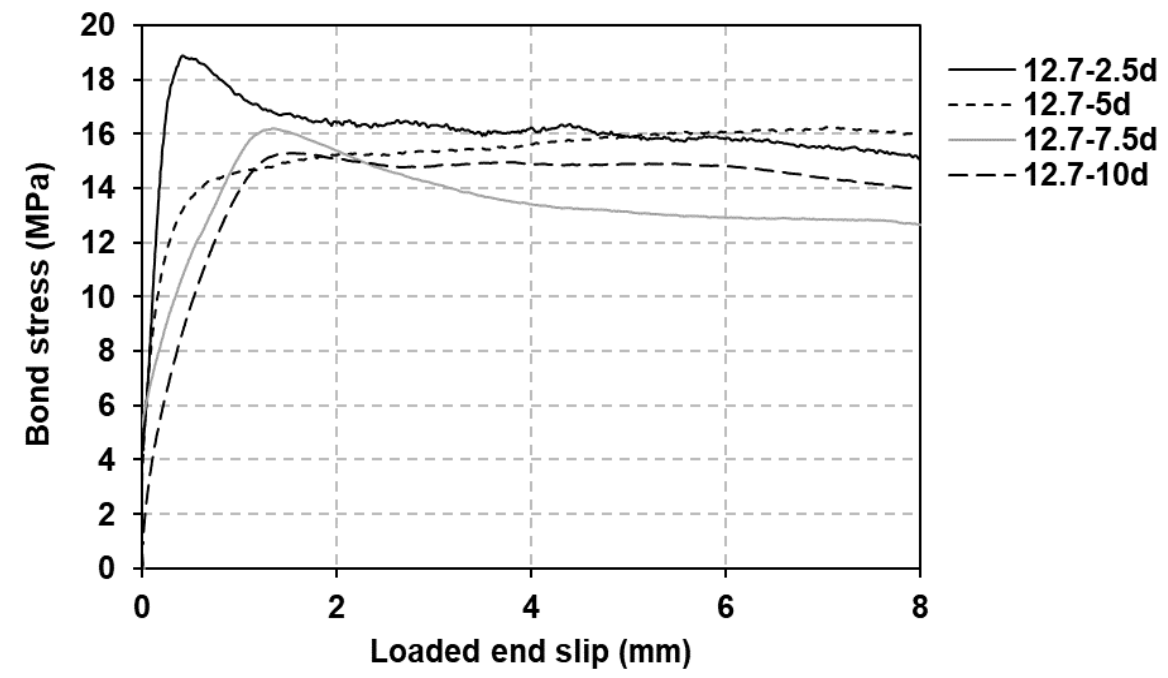

(a)

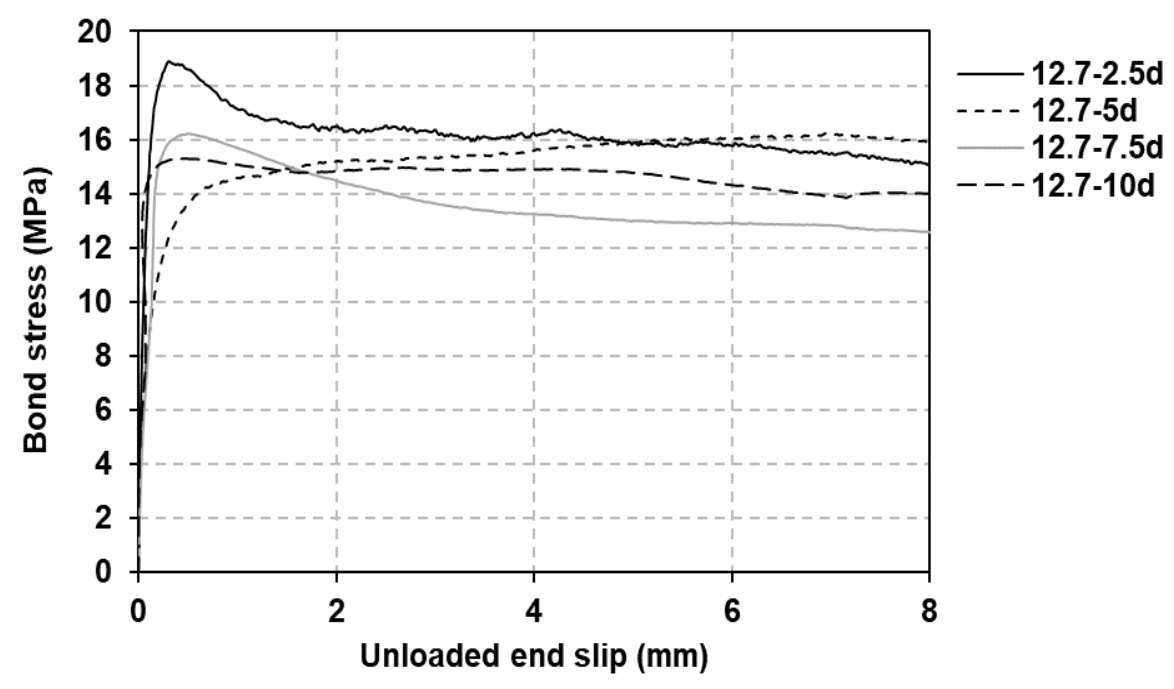

(b)

Figure 5. Bond stress - slip relationship for $12.7 \mathrm{~mm}$ GFRP (type A) reinforced cubes: (a) loaded and (b) unloaded end slips 


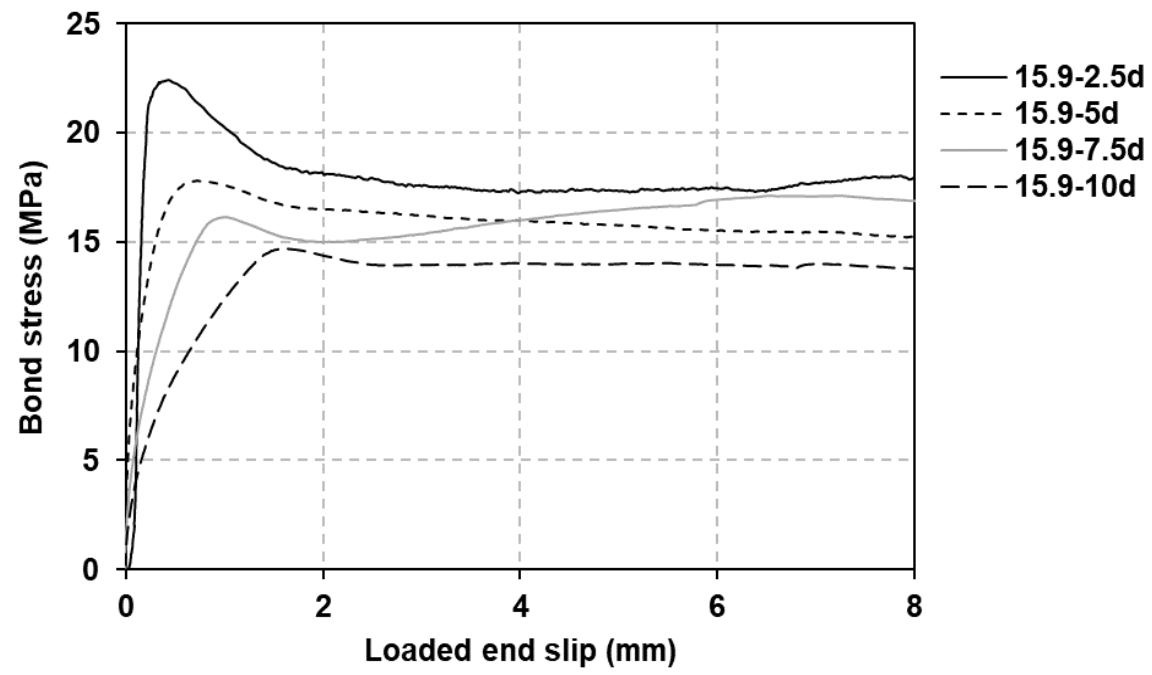

302

(a)

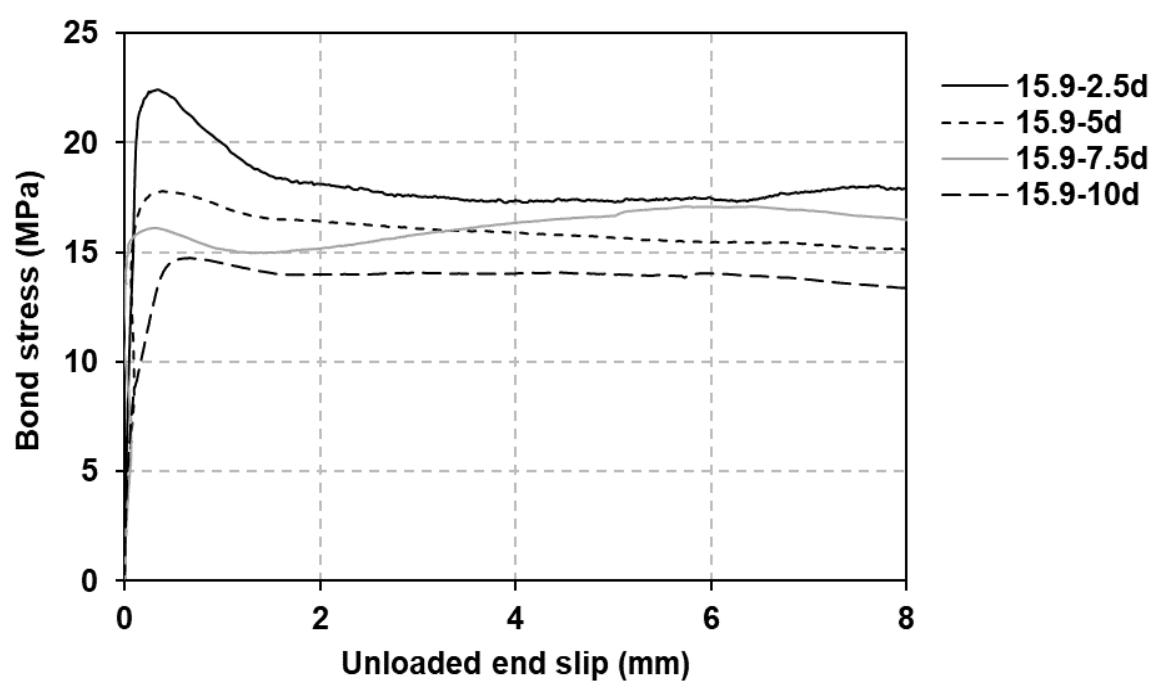

Figure 6. Bond stress - slip relationship for 15.9 mm GFRP (type A) reinforced cubes: (a) loaded and (b) unloaded end slips 
308

309

310

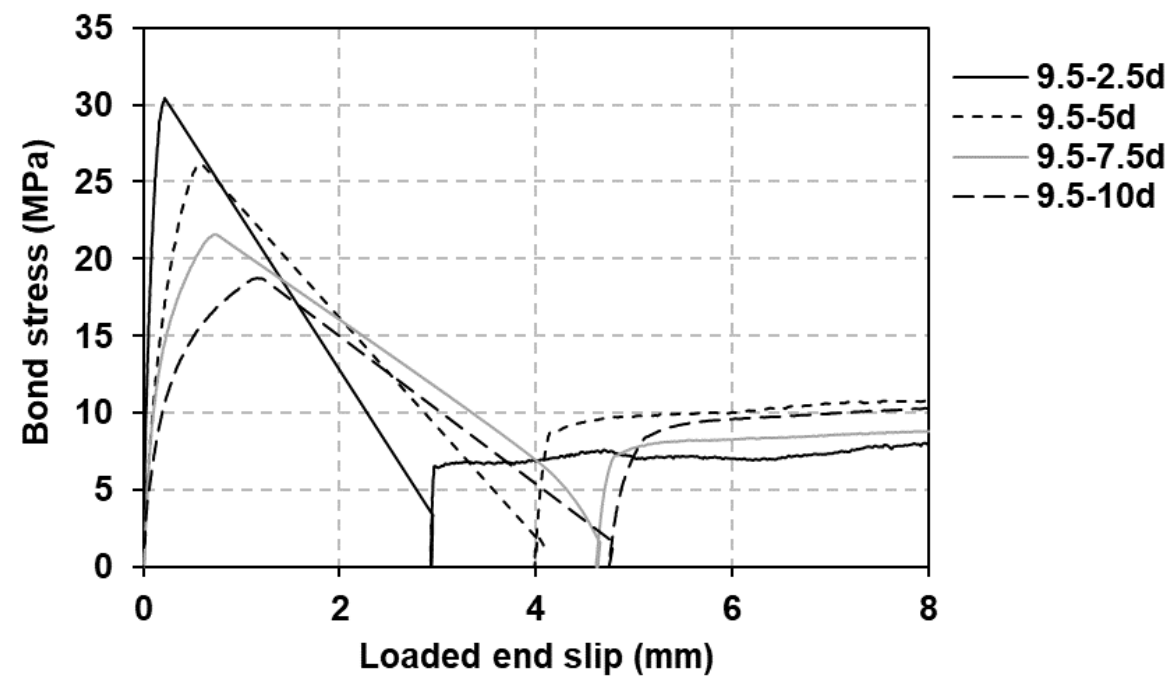

(a)

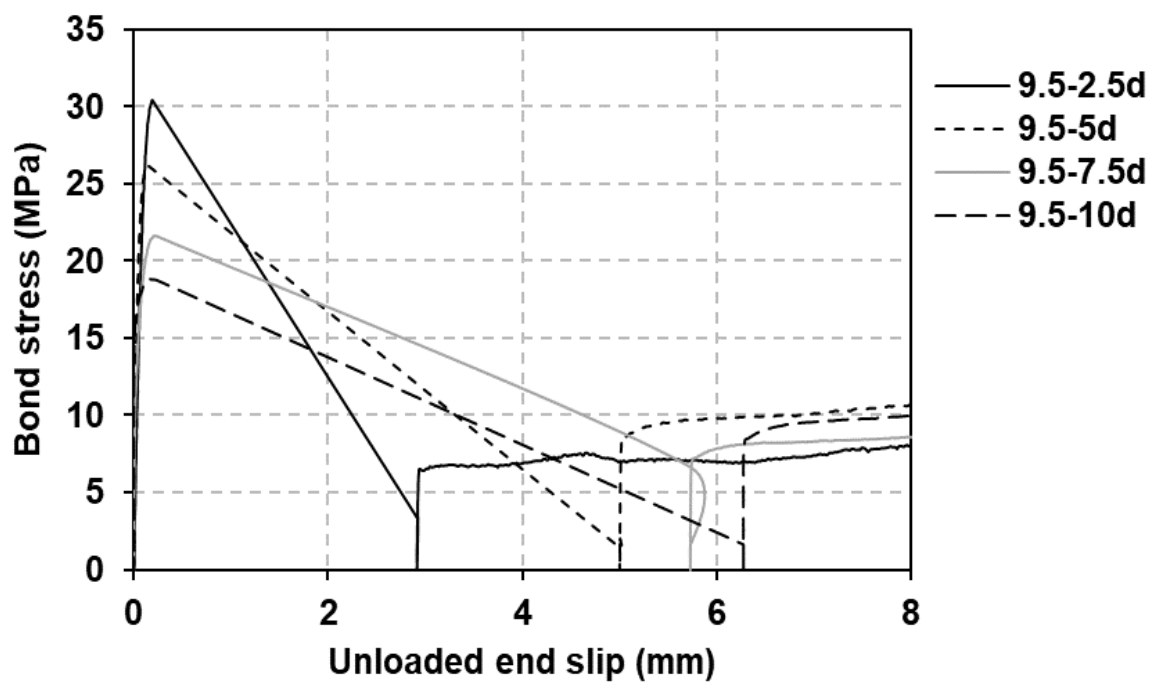




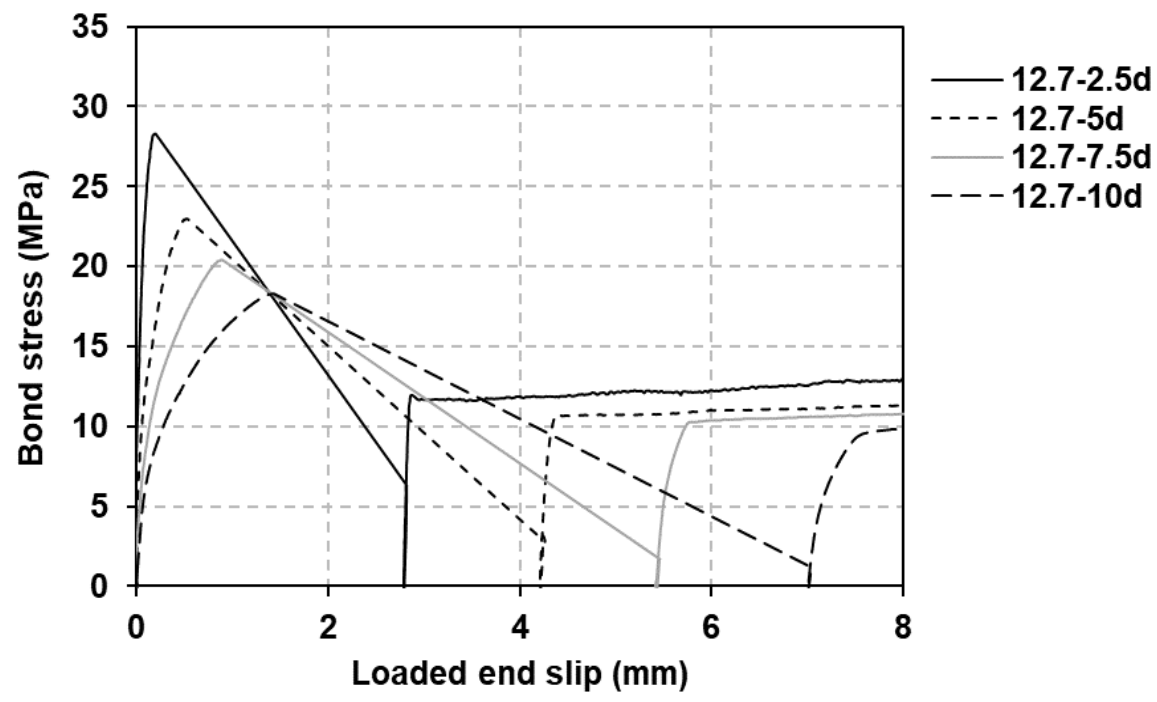

(a)

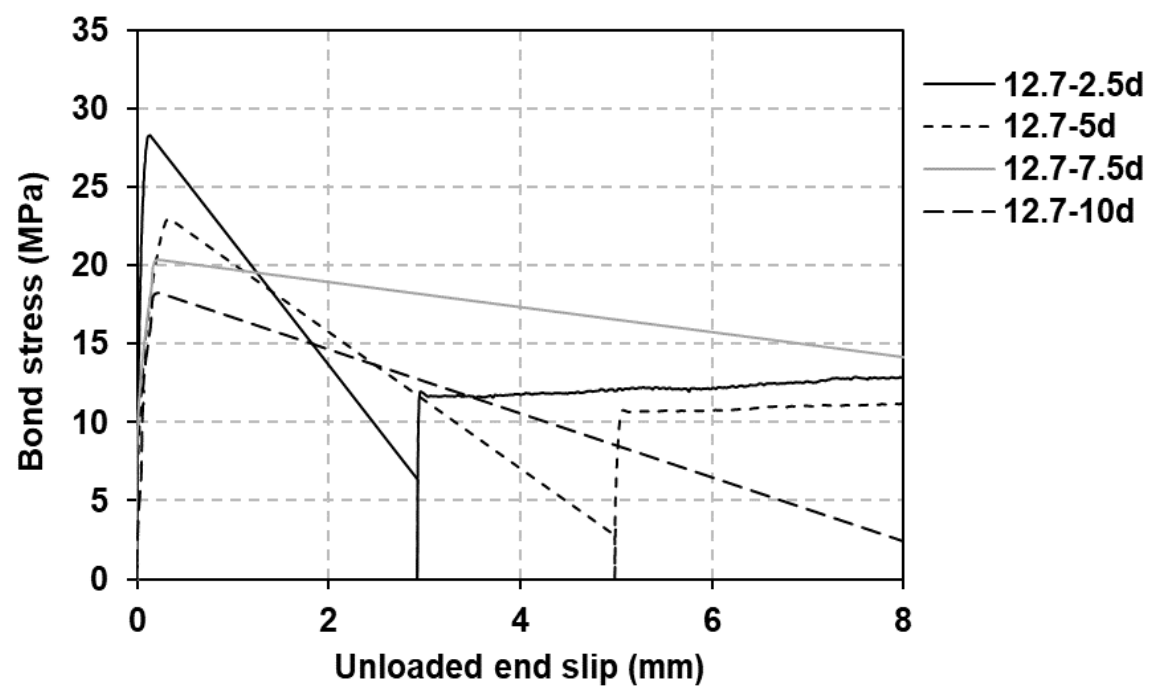

(b)

Figure 8. Bond stress - slip relationship for $12.7 \mathrm{~mm}$ GFRP (type B) reinforced cubes: (a) loaded and (b) unloaded end slips 


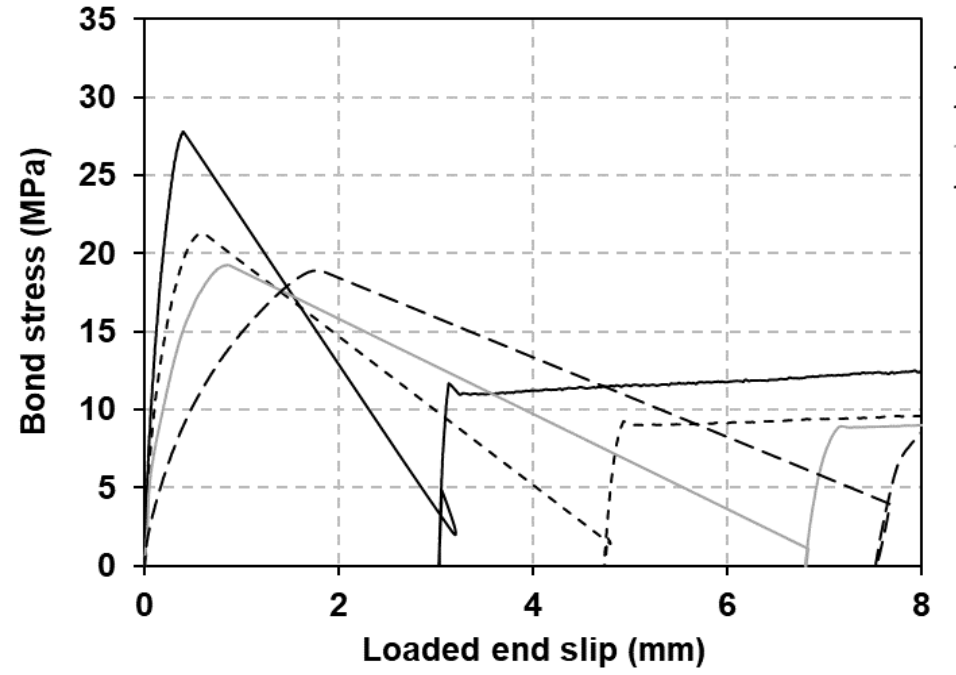

(a)

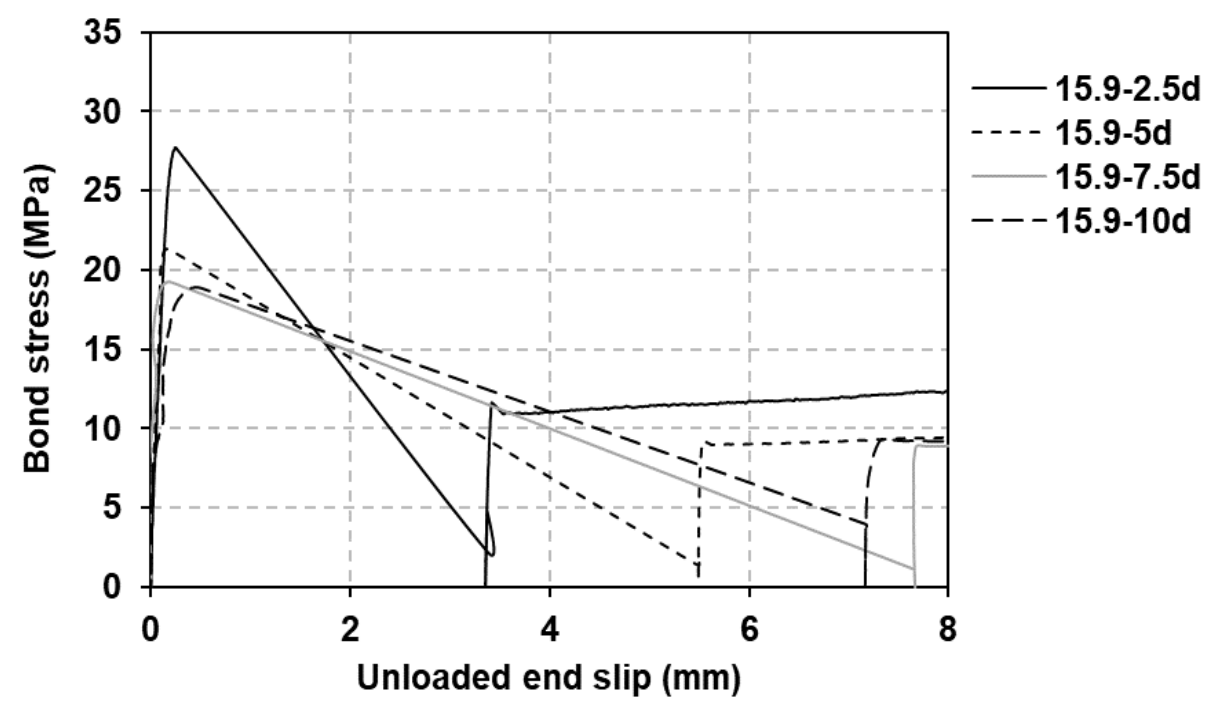

(b)

Figure 9. Bond stress - slip relationship for $15.9 \mathrm{~mm}$ GFRP (type B) reinforced cubes: (a) loaded and (b) unloaded end slips 15.9-2.5d
$---15.9-5 d$

15.9-7.5d

$---15.9-10 d$ 


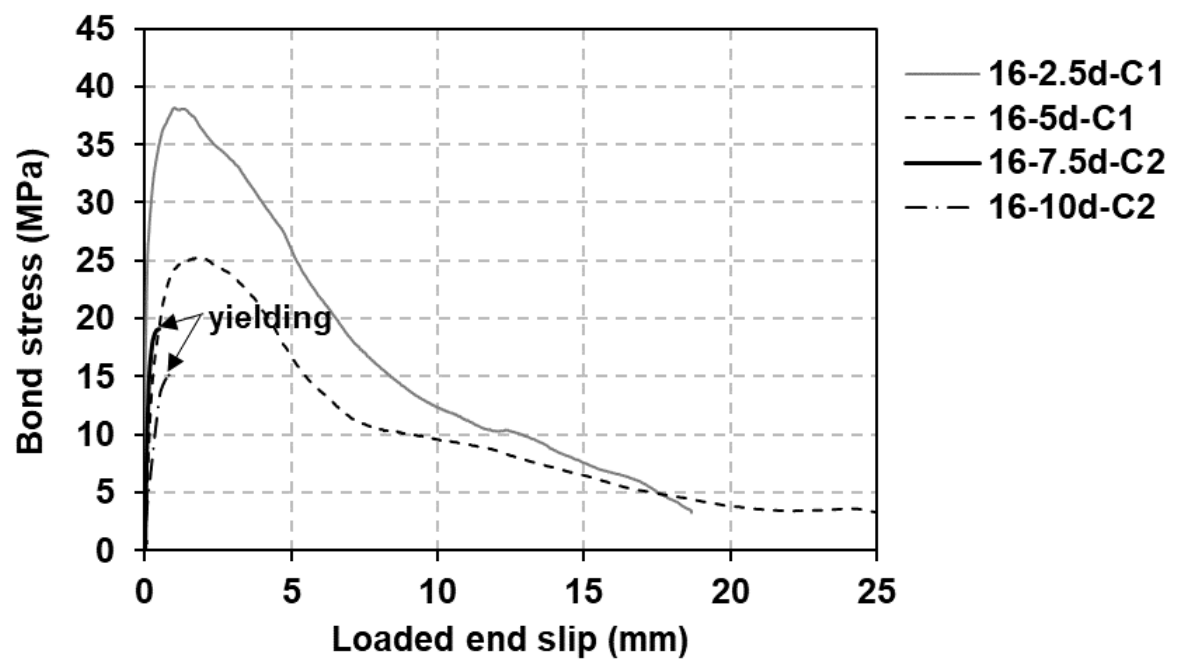

(a)

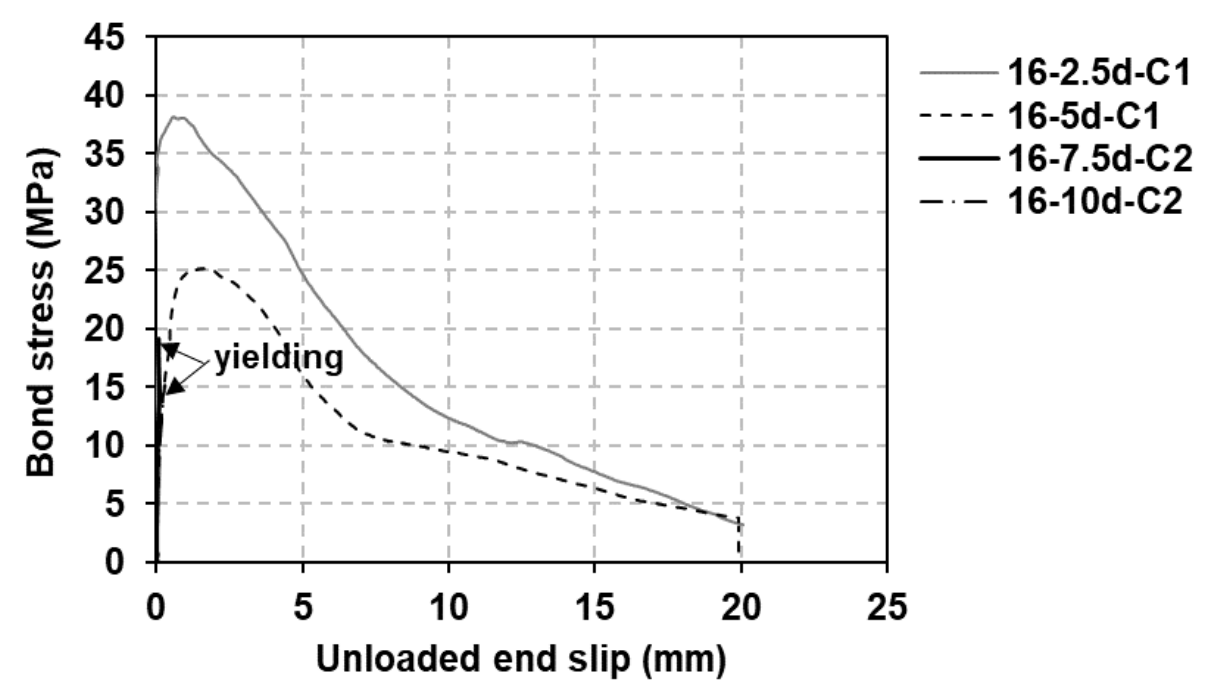

(b)

Figure 10. Bond stress - slip relationship for $16 \mathrm{~mm}$ steel reinforced cubes: (a) loaded and (b) unloaded end slips

\subsection{Initial stiffness of bond stress - slip curves}

Figure $11(a$ and $b)$ shows that the initial stiffness reduces with increasing the embedment

342 length as reported by Pepe et al. [31] and Achillides and Pilakoutas [1]. This might be 343 attributed to the non-uniform distribution of bond stresses along the bonded length. Also, 344 it is found that the initial stiffness of steel bars is higher than that of GFRP (HW-SC) bars 
as shown in Figure 4.11 (a). This may be because of the differing surface properties and 346 elastic modulus. This result was also confirmed by Baena et al. [5] from testing the pull347 out cubes reinforced with different rebar types (glass FRP, carbon FRP and steel).

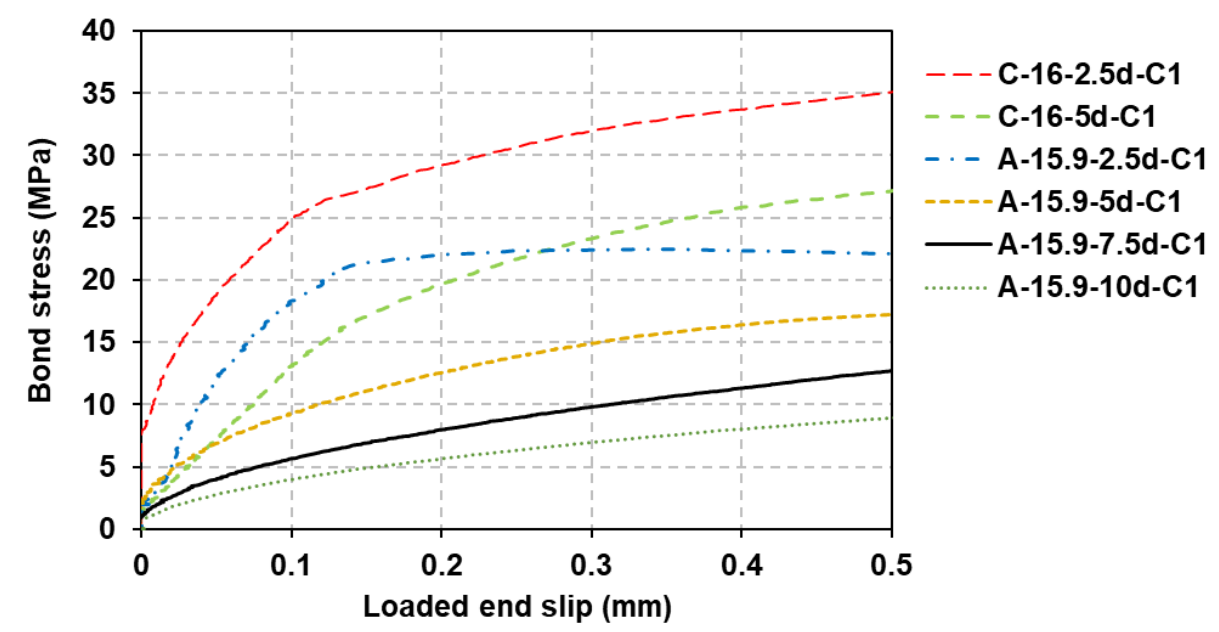

(a)

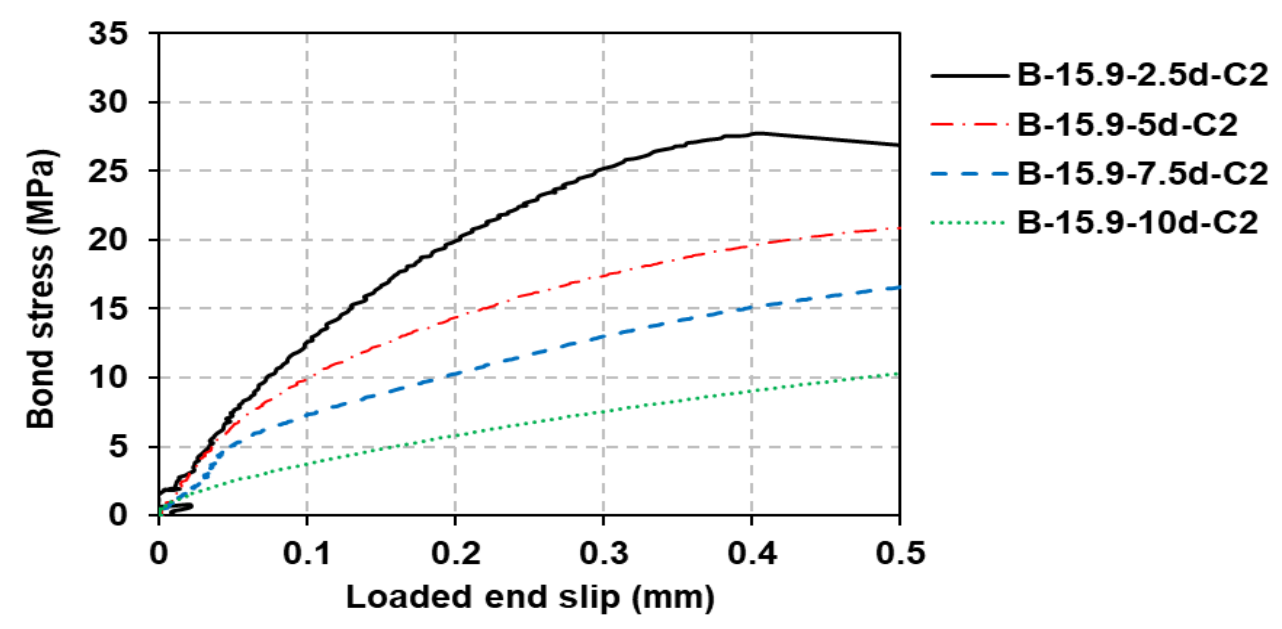

(b)

Figure 11. Influence of elastic modulus and embedment length of bar on initial stiffness

\subsection{Bond failure mechanism}

355 The failure mode observed for each pull-out test is listed in Tables $\underline{4}$ and 5. As anticipated, most specimens were failed by a pull-out mode as shown in Figure 12, because the cube 
compressive strength of concrete was designed to be higher than $80 \mathrm{MPa}$ to ensure the 358 occurrence of failure at the bar - concrete interface, rather than in the concrete. However, 359 the specimens reinforced with steel bars, having the embedment lengths of $7.5 d_{b}$ and $36010 d_{b}$, failed by bar fracture before attaining the bond strength as presented in Figure 14 361 (b). It can be concluded that the development length required to avoid bond failure 362 between the high-strength concrete and steel bars could be equal to or more than $7.5 d_{b}$. 363 The specimens were split after testing to visually assess the bar and surrounding concrete 364 conditions. As for the specimens reinforced with GFRP (HW-SC) bars, some abrasions were noted on the outer surface with stripping of sand coating as shown in Figure 13 (b). White residue was seen on the trace of the whole embedment length, which indicated 367 crushing of the resin. As noted, the specimens with longer embedment lengths failed by bonding failure in the sand coated GFRP reinforced specimens occurred by the entire 371 detachment of the sand coated layer accompanied with a loud bang, when bond stress 372 reached the peak value as demonstrated in Figure 13 (c). The concrete also remained uncrushed. This indicated that the bond strength between the outer layer and bar core 374 was lower than that between the high-strength concrete and sand coating. Therefore, 375 failure was controlled by the shear strength at the resin - bar core interface rather than 376 the shear strength between the bar and concrete. This mode of failure was expected in 377 the case of high-strength concrete. Similarity, Baena et al. [5] found that the sand coated 378 layer was totally stripped from the GFRP-SC rebar, when the compressive strength of 379 concrete was around $50 \mathrm{MPa}$. The specimens with a concrete strength of $30 \mathrm{MPa}$ failed 380 by a pull-out mode due to damage in the concrete surface. Concerning steel reinforced 
381 cubes failed by pull-out, Figure 14 (a) shows the remaining concrete still attached to the 382 outer surface of steel rebar. This is an indicator that bond failure occurred by shearing off 383 of the concrete between ribs.

384

385

386

387

388

389

390

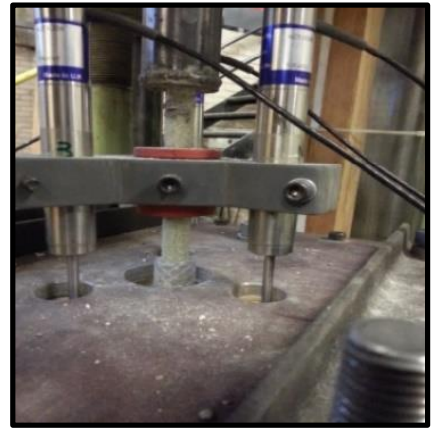

Figure 12. Pull-out failure

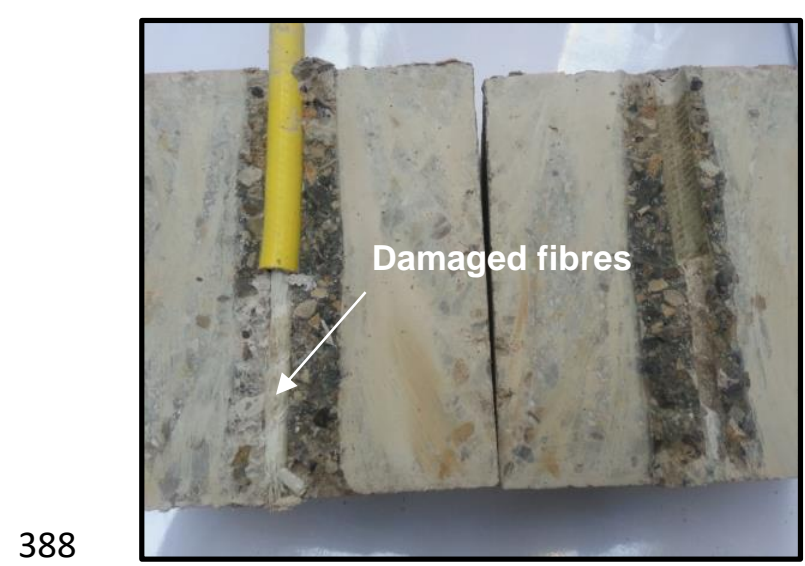

(a) Cube (A-9.5-10d)

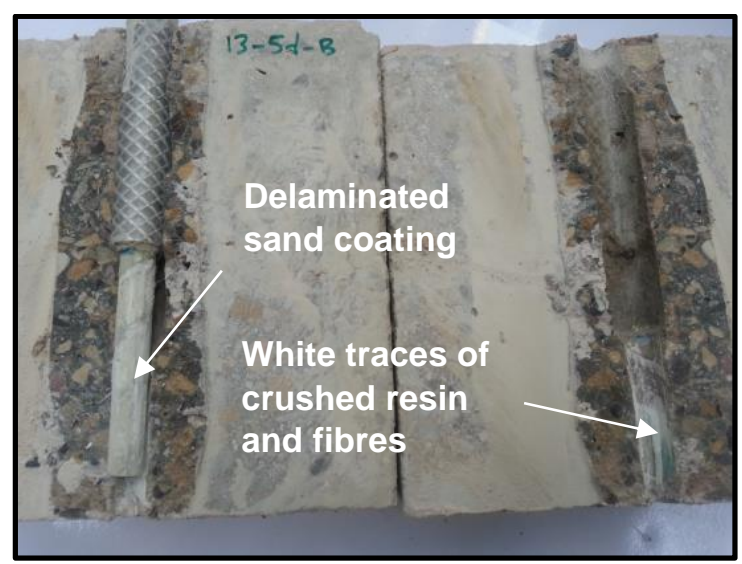

(b) Cube (A-12.7-5d) 
(a) Shear off concrete in cube (C-16-2.5d)

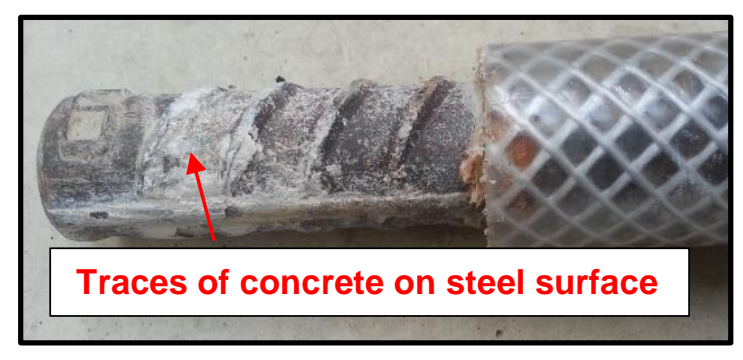

Figure 14. Visual inspection of specimens reinforced with steel bars

\subsection{Factors influencing bond strength}

\subsubsection{Effect of embedment length on bond strength}

Generally, the trend of the test results points out that the longer the embedment length, the smaller the value of the average bond strength, irrespective of bar diameter in both GFRP types as well as steel bars. On the other hand, as expected, the failure load increases with increasing the embedment length. The relationships between the bond strength and embedment length are shown in Figures 15 and 16 for GFRP (type A) and

407 GFRP (type B) reinforced cubes with different bar diameters, respectively. Based on the 408 experimental results, it can be reported that the bond strength increases with reducing the 409 bonded length and this observation was also confirmed by some previous authors [1, 2, 
$4107,13,14]$. This is attributed to two main factors: 1 ) non-linear distribution of bond stress

411 along the embedment length, and 2) the reduction in the bar size due to the Poisson's

412 ratio effect, leading to reductions in the frictional and mechanical interlock resistances

413 along the embedment length. In Figure 15, it is noted that no significant change occurred

414 in the bond strength with the increase of embedment length for smaller bar diameters. For

415 example, the bond strength of a $9.5 \mathrm{~mm}$ GFRP (HW-SC) bar having an embedment length

416 of $10 d_{b}$ is reduced by approximately $6 \%$ compared to that having an embedment length

417 of $2.5 d_{b}$. However, for larger bar diameters, the reduction rates in the bond strength of

$41810 d_{b}$ specimens were $19 \%$ and $24 \%$ compared to $2.5 \mathrm{db}$ specimens, for 12.7 and 15.9

$419 \mathrm{~mm}$ bar diameters, respectively. In Figure 16, the bond strength of $10 d_{b}$ specimens 420 having $9.5,12.7$ and $15.9 \mathrm{~mm}$ diameters is decreased by almost $34 \%, 36 \%$ and $32 \%$ in

421 comparison with $2.5 d_{b}$ specimens, respectively. In general, the reduction rate in bond 422 strength of GFRP (type B) is higher than the reduction rate in bond strength of GFRP (type 423 A). For comparison purposes, steel reinforced specimens also were tested to compare 424 their bond strength with those reinforced with GFRP re-bars. It was found that the bond 425 strength of GFRP (type A) bars was lower (50 to 65\%) than that of steel bars, depending 426 on embedment length. This is because of different mechanical properties and surface 427 configurations. Regarding $7.5 \mathrm{~d}_{\mathrm{b}}$ and $10 \mathrm{~d}_{\mathrm{b}}$ steel reinforced cubes, the failure observed was 428 a bar rupture instead of a pull-out bar. Subsequently, these specimens did not compare 429 with counterparts reinforced with GFRP (type B) bars. It was noticed that the loaded end 430 slip increased with increasing the embedment length for the same bar diameter in both 431 GFRP types. The same observation was reported by Pepe et al. [31] from testing hinged 432 beams and Tekle et al. [14] from testing pullout specimens. 


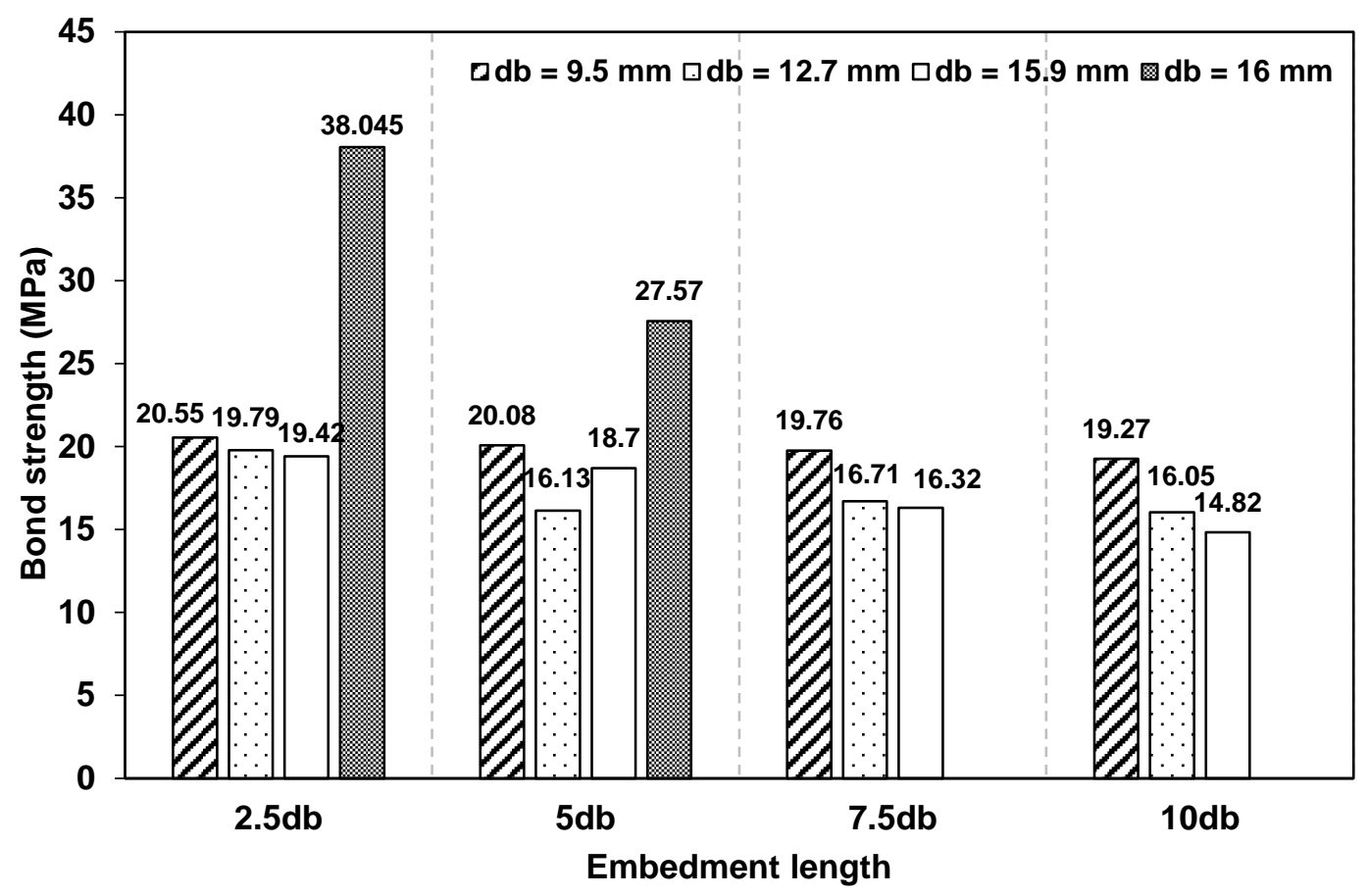

434 435 436
Figure 15. Effect of the embedment length and bar diameter on the average bond strength of GFRP (HW-SC) bars embedded in HSC cubes

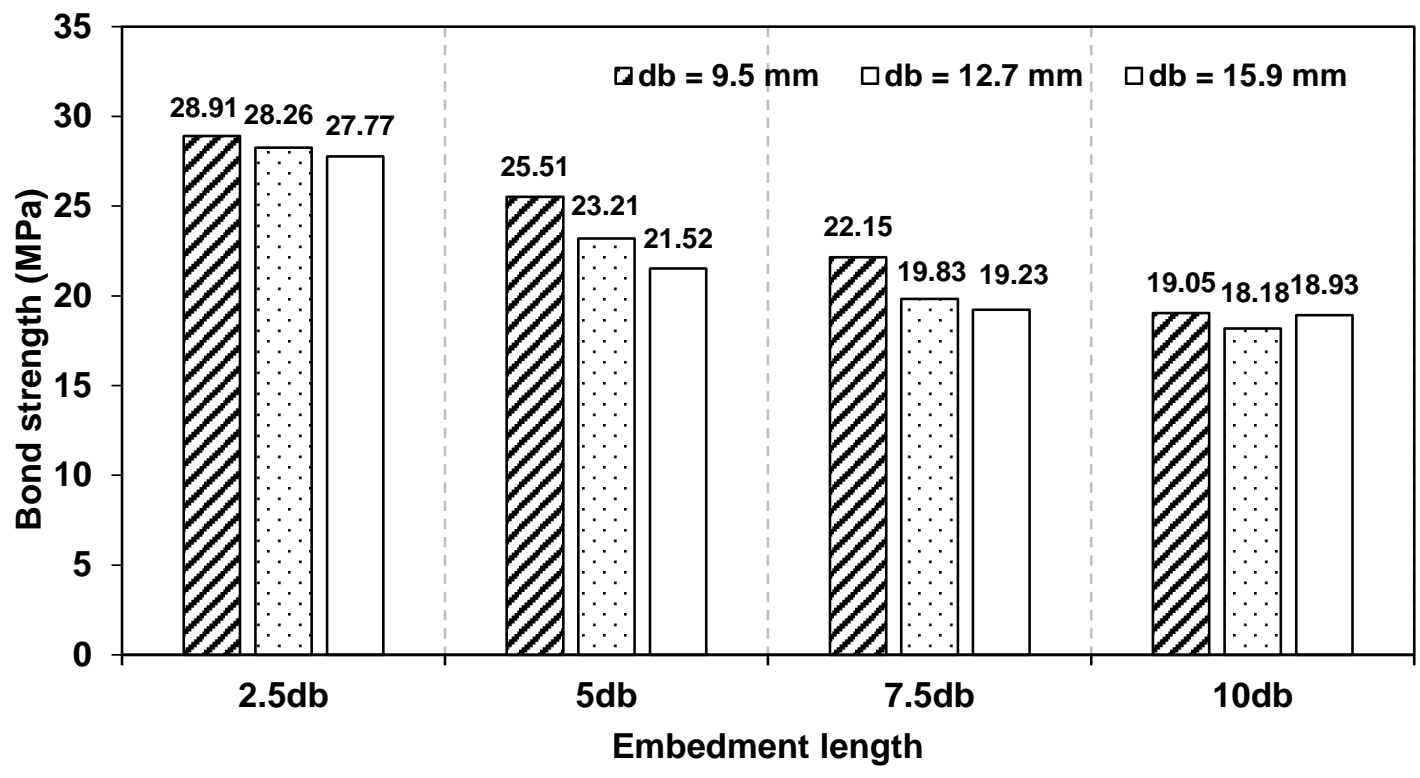

Figure 16. Effect of the embedment length and bar diameter on the average bond strength of GFRP (SC) bars embedded in HSC cubes 


\subsubsection{Effect of the bar diameter on bond strength}

446 As shown in Figures 15 and 16, the average bond strength of GFRP bars reduces with 447 increasing the bar diameter similar to steel bars. This observation is valid for all test 448 specimens regardless of the embedment length. This trend was also reported by Nanni 449 et al. [32], Benmokrane et al. [33], Cosenza et al. [34], Tighiouart et al. [16], Achillides 450 [35], Achillides and Pilakoutas [1], Okelo and Yuan [2], Tepfers [36], Xue et al. [37], Baena 451 et al. [5], Hossain et al. [13], El Refai et al. [7] and Lee et al. [15]. This is attributed to the 452 nonlinear distribution of bond stresses along the embedment length [1, 5, 33], which is 453 more pronounced in larger bar diameters as longer embedment lengths are required. In 454 addition, Achillides and Pilakoutas [1] reported that the Poisson effect may have an effect 455 on this behaviour by reducing the bar diameter subjected to the pull-out load; this 456 reduction in bar diameter increases with the bar size. Subsequently, the frictional and 457 mechanical interlock stresses decrease along the embedment length. Shear lag was also 458 considered as a factor in explaining this phenomenon. The non-linear distribution of normal stresses through the cross-section of the bar increases with increasing bar 460 diameter with normal stresses at bar surface higher than those closer to centre, violating 461 the average bond strength [1]. From Figure 15, GFRP (type A) bars with $9.5 \mathrm{~mm}$ diameters 462 showed bond strengths $5.5 \%, 6.9 \%, 17.4 \%$ and $23.1 \%$ higher than the bond strengths 463 developed by the $15.9 \mathrm{~mm}$ diameters for the embedment lengths of $2.5,5,7.5$ and 10 464 times the bar diameter, respectively, with an average increase of $13.2 \%$. It can be stated 465 that the decrease of bar diameter led to a slight increase in the bond strength for the 466 shorter embedment lengths. These percentages were $3.7 \%, 19.6 \%, 15.4 \%$ and $16.7 \%$ 467 more than the bond strengths developed by the $12.7 \mathrm{~mm}$ bar diameters for the same 468 embedment lengths, with an average increase of $13.8 \%$. As can be seen in Figure 16, 
GFRP (type B) bars with $12.7 \mathrm{~mm}$ bar diameters showed bond strengths that were $2.3 \%$,

$4709 \%, 10.4 \%$ and $4.5 \%$ lower than those developed by $9.5 \mathrm{~mm}$ bar diameters for the

471 embedment lengths of 2.5, 5, 7.5 and 10 times the bar diameter, respectively, with an

472 average reduction of $6.5 \%$. As for $15.9 \mathrm{~mm}$ diameters, these percentages were $4.1 \%$,

$47318.5 \%, 15.2 \%$ and $0.6 \%$ less than those developed by $9.5 \mathrm{~mm}$ diameters for the same

474 embedment lengths, with an average reduction of $9.6 \%$. For high-strength concrete pull-

475 out cubes, it was noticed that a reduction rate in bond strength reduced with increasing

476 the bar diameter for all embedment lengths. A similar observation was confirmed by Lee

477 et al. [15] and they also reported that the influence of bar diameter on bond strength was

478 affected by concrete compressive strength.

\section{3.4.3 Effect of bar surface treatment on bond strength}

480 Due to the important influence of the surface properties on bond behaviour, it is worth 481 comparing the bond performance of different surface treatments. From Figure 17, it can be seen that the bond strength of GFRP (SC) bars is higher than that of GFRP (HW-SC)

483 bars due to their sand coated surface, which is similar to the results obtained from testing 484 pull-out specimens for cylinder compressive strengths of concrete in the range of 57 to 63 $\mathrm{MPa}$ [11]. The bond strength of GFRP (SC) bars strongly depends on friction resistance 486 provided by surface treatment, while little bearing resistance was provided by GFRP (HWSC) bars, unlike steel bars. However, according to the findings of Baena et al. [5], the 488 bond strength of GFRP (HW-SC) bars was higher than that of GFRP (SC) bars for a concrete strength of $53 \mathrm{MPa}$, despite the fact that the GFRP bars used were similar to the GFRP bars used in the current study. Moreover, Baena et al. [5] reported that the influence 
492 effect was less important in low - strength concrete compared to high - strength concrete.

493 In addition, Lee et al. [12] found that bond strengths achieved by GFRP (HW-SC) re-bars

494 were greater than those achieved by GFRP (SC) re-bars for different concrete strengths

495 of 25,40 and $70 \mathrm{MPa}$. As illustrated in Figure 17, the ratio of GFRP (type B) bond strength

496 to GFRP (type A) bond strength varied from 0.99 to 1.44 with an average of 1.25 ,

497 depending on bar diameter and embedment length. It was also noted that the 498 corresponding loaded end slip in GFRP (SC) bars is smaller than that in GFRP (HW-SC)

499 bars as shown in Tables $\underline{4 \text { and } 5}$. The same observation was reported by Lee et al. [12].

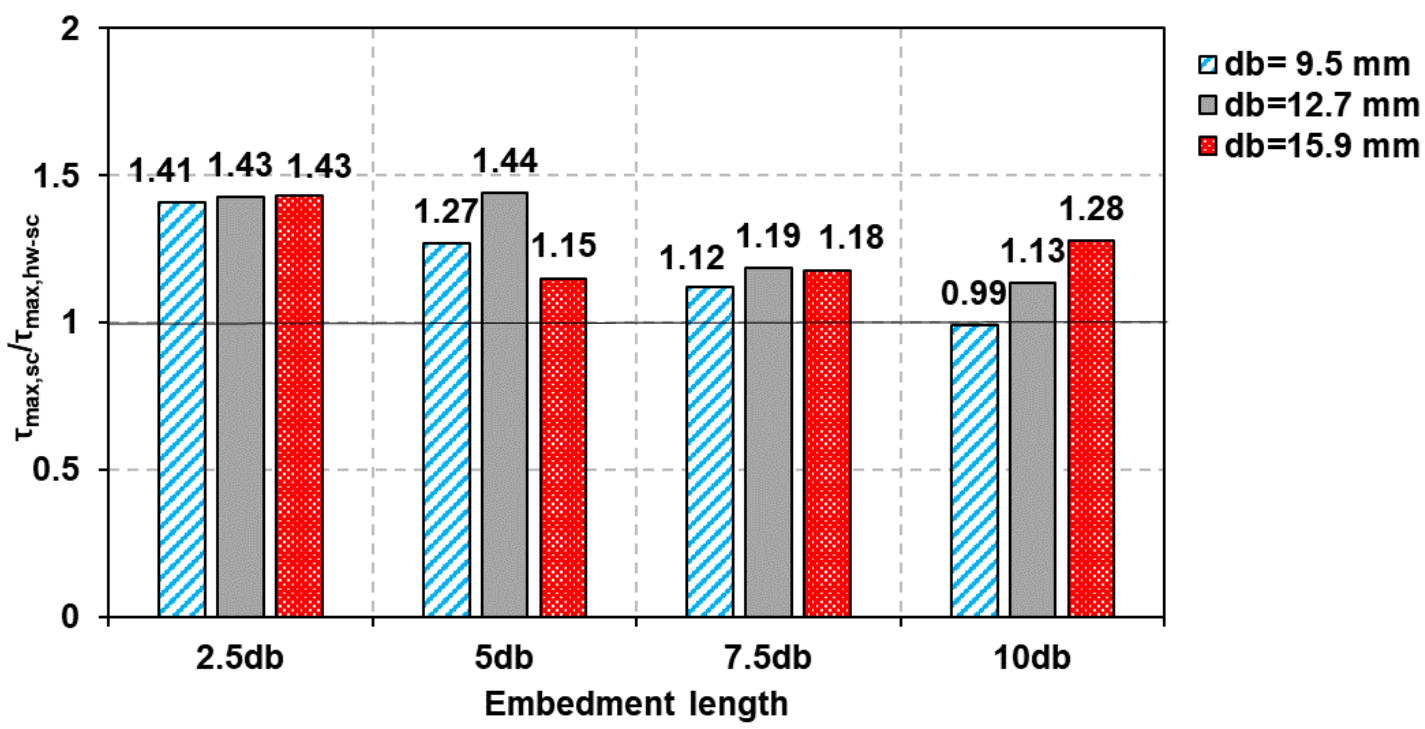

Figure 17. Comparison between bond strength of GFRP (SC) bars and bond strength of GFRP (HW-SC) bars for HSC cubes

\section{$4 \quad$ Comparison of test results with current codes}

For comparison purposes, the bond strengths provided by code equations were determined based on the geometrical and mechanical properties of the pull-out cubes.

508 The ACI-440.1R [21] code proposed an equation for GFRP bars based on the work 509 conducted by Wambeke and Shield [38] as below: 


$$
\frac{\tau_{\max }}{0.083 \sqrt{f_{\mathrm{c}}^{\prime}}}=4+0.3 \frac{\mathrm{c}}{\mathrm{d}_{\mathrm{b}}}+100 \frac{\mathrm{d}_{\mathrm{b}}}{\mathrm{l}_{\mathrm{e}}}
$$

where $\tau_{\max }$ is the bond strength $(\mathrm{MPa}), f_{\mathrm{c}}^{\prime}$ is the cylinder compressive strength of concrete

$(\mathrm{MPa})$ and $\mathrm{c}$ is the lesser of the cover to the centre of the bar or one-half of the centre-to-

514 centre spacing of the bars being developed $(\mathrm{mm})$. The ratio of $\mathrm{c} / \mathrm{d}_{\mathrm{b}}$ is limited to be less

515 than 3.5. The CAN/CSA-S806 [22] and CAN/CSA-S6 [23] Canadian codes have also

516 proposed the expressions for estimating the development length of FRP bars in

517 conventional concrete in order to avoid bond failure. These equations were substituted in

518 equation 1 to produce the expressions 5 and 6 for CAN/CSA-S806 and CAN/CSA-S6, 519 respectively, which are used to calculate bond strength.

524 where:

$$
\tau_{\max }=\frac{\mathrm{d}_{\mathrm{cs}} \sqrt{\mathrm{f}_{\mathrm{c}}^{\prime}}}{1.15 \mathrm{k}_{1} \mathrm{k}_{2} \mathrm{k}_{3} \mathrm{k}_{4} \mathrm{k}_{5} \pi d_{b}}
$$

where $\mathbf{k}_{1}$ is a bar location factor ( 1.3 for horizontal reinforcement placed so that more than $300 \mathrm{~mm}$ of fresh concrete is cast below the development length or splice, 1.0 for other

529 cases), $\mathbf{k}_{\mathbf{2}}$ is a concrete density factor (1.3 for structural low-density concrete, 1.2 for 530 structural semi-low-density concrete, 1.0 for normal density concrete), $\mathbf{k}_{3}$ is a bar size 531 factor ( 0.8 for $A_{b} \leq 300 \mathrm{~mm}^{2}, 1.0$ for $\left.A_{b}>300 \mathrm{~mm}^{2}\right), \quad \mathbf{A}_{\mathbf{b}}$ is the cross-sectional area of 532 FRP bar $\left(\mathrm{mm}^{2}\right), \mathbf{k}_{4}$ is a bar fibre factor ( 1.0 for GFRP), $\mathbf{k}_{5}$ is a bar surface factor ( 1.0 for 533 surface-roughened or sand-coated surfaces and 1.05 for spiral pattern surface), $\mathbf{k}_{6}$ is a 534 bar surface factor, being the ratio of the bond strength of the FRP bar to that of a steel 
535 deformed bar with the same cross-sectional area as the FRP bar, but not greater than 1.0.

536 In the absence of experimental data, $k_{6}$ shall be taken as $0.8, \mathbf{d}_{\mathbf{c s}}$ is the smaller of the

537 cover to the centre of the bar or two-thirds of the centre-to-centre spacing of the bars 538 being developed $(\mathrm{mm})$ (not greater than $2.5 \mathrm{~d}_{\mathrm{b}}$ ), $\boldsymbol{k}_{t r}$ is a transverse reinforcement index, $539 \boldsymbol{A}_{t r}$ is the cross-sectional area of transverse reinforcement $\left(\mathrm{mm}^{2}\right), \mathbf{s}$ is the maximum 540 spacing centre to centre of the transverse bars within $l_{d}(\mathrm{~mm}), \boldsymbol{f}_{y t}$ is the yield stress in the 541 transverse reinforcement $(\mathrm{MPa}), \mathbf{n}$ is the number of bars being developed along the 542 potential plane of bond splitting, $\boldsymbol{f}_{c r}$ is the cracking strength of concrete $(\mathrm{MPa})\left(0.4 \sqrt{f_{c}^{\prime}}\right.$ for 543 normal-density concrete, $0.34 \sqrt{f_{c}^{\prime}}$ for semi-low-density concrete, $0.3 \sqrt{f_{c}^{\prime}}$ for low-density 544 concrete), $\mathbf{E}_{\mathrm{frp}}$ and $\mathbf{E}_{\mathbf{s}}$ are the modulus of elasticity of FRP and steel bars, respectively. 545 The square root of concrete strength should be less than 5 and $8 \mathrm{MPa}$ for CSA-S806 and 546 CSA-S6, respectively.

547 The Japanese Design Code [24] suggested equation 7 to evaluate the bond strength of 548 FRP bars to concrete:

$$
\tau_{\max }=\frac{f_{\text {bod }}}{\alpha_{1}}
$$

550 where:

$$
f_{\text {bod }}=0.28 \alpha_{2} f_{c}^{, 2 / 3} / 1.3 \leq 3.2 \mathrm{~N} / \mathrm{mm}^{2}
$$

552 where $\boldsymbol{f}_{\boldsymbol{b o d}}$ is the design bond strength of concrete (MPa), $\boldsymbol{\alpha}_{2}$ is the modification factor 553 for the bond strength of CFRM (= 1 when the bond strength of CFRM is equal to or greater 554 than that of the deformed steel bars); otherwise $\alpha_{2}$ shall be decreased according to the 555 test results, $\boldsymbol{\alpha}_{\mathbf{1}}$ is a confinement modification factor (= 1 when $k_{c} \leq 1 ; 0.9$ when $1<k_{c} \leq$ $5561.5 ; 0.8$ when $1.5<k_{c} \leq 2 ; 0.7$ when $2<k_{c} \leq 2.5$ and 0.6 when $k_{c}>2.5$ ), $k_{c}$ is specified 
557 as $\left(=\frac{c}{d_{b}}+\frac{15 A_{t r}}{s d_{b}}+\frac{E_{t}}{E_{s}}\right), \mathbf{c}$ is the smaller of the bottom clear cover of the main reinforcement 558 or half of the clear space between the reinforcement being developed (mm), $\boldsymbol{A}_{t r}$ is the 559 cross-sectional area of the transverse reinforcement $\left(\mathrm{mm}^{2}\right), \mathbf{s}$ is the maximum spacing 560 centre to centre of the transverse bars within $l_{d b}(\mathrm{~mm}), \boldsymbol{E}_{\boldsymbol{t}}$ is Young's modulus of elasticity 561 for the transverse reinforcement (MPa) and $\boldsymbol{E}_{\boldsymbol{s}}$ is Young's modulus for steel (MPa).

562 Tables $\underline{6 \text { and } 7}$ summarize the comparative results of the experimental bond strengths of 563 various specimens with the predicted bond strengths calculated from the methods 564 provided in ACl 440.1R-15, CSA-S806-12, CSA-S6-14 and JSCE [24]. In Figure 18 (a to $565 \underline{\text { c) }}$, the predictions provided by the ACI 440.1R, CSA-S806, CSA-S6 and JSCE equations 566 were plotted using the geometrical and mechanical properties of the pull-out cube in the present study. It can be seen that the $\mathrm{ACl} 440.1 \mathrm{R}$ code overestimates the bond strength 568 of both GFRP bars having an embedment length of $2.5 \mathrm{db}$, while it is conservative for larger 569 embedment lengths. The average ratio of experimental to predicted bond strengths 570 obtained from the $\mathrm{ACl} 440.1 \mathrm{R}$ code is 1.06 with a COV of $34.3 \%$ and 1.45 with a COV of 57125.6 for GFRP (type A) and GFRP (type B) reinforced cubes, respectively. CSA-S806, 572 CSA-S6 and JSCE codes are too conservative, where the average ratios of experimental 573 to predicted bond strengths for GFRP (type A) reinforced cubes are 4.41, 2.56 and 3.4 574 with a COV of $10.9 \%$, respectively. They are $5.26,3.21$ and 4.26 with a COV of $17.4 \%$ for 575 GFRP (type B) reinforced cubes. Tables $\underline{6}$ and 7 show that the bond strength obtained 576 from Canadian and Japanese codes is not influenced by bar diameter and embedment 577 length because of the limitations of $d_{c s}$ and $k_{c}$ in the Canadian and Japanese codes, 578 respectively, as well as ignoring the effect of the embedment length on bond strength in 579 both codes. This conclusion was also confirmed by Hossain et al. [13], by comparing test 
results with the Canadian code predictions. In contrast to the Canadian codes, the bond 581 strength reduces with increasing embedment length as per the $\mathrm{ACl} 440.1 \mathrm{R}$ code. No 582 change was noted in the $\mathrm{ACI} 440.1 \mathrm{R}$ predictions for identical specimens with the only one 583 variable being bar diameter, and this is due to the limitation of the ratio of $c / d_{b}$ and the 584 value of the embedment length, that was taken as the ratio of the bar diameter, and this 585 led to cancel the effect of bar diameter represented by $d_{b} / l_{e}$. However, from Tables $\underline{6 \text { and }}$ $586 \underline{7,}$, there is a slight change in bond strength with the increase of bar diameter for the cubes 587 with the same embedment length, because of a small variation of concrete strength. The $588 \mathrm{ACl} 440.1 \mathrm{R}$ code does not acknowledge the influence of surface properties on bond strength. However, experimental results of GFRP (type A) and GFRP (type B) reinforced 590 specimens plotted in Figure 18 (a) revealed that bond strength of GFRP (type B) bars is 591 slightly higher than that of GFRP (type A) bars owing to the difference of surface 592 configuration. It was noticed that the tested results for helical wrapped with slightly sand 593 coated GFRP bars were closer to the ACl 440.1R predicted curve than the tested results 594 for sand coated GFRP (SC) bars. This may be attributed to the fact that the ACI 440.1R 595 equation was developed based on existing database containing limited surface types of 596 only two (spiral wrapping and helical lugs). The Japanese design code also neglects the 597 effect of surface configuration on bond strength. On the contrary, the Canadian codes 598 acknowledge the effect of bar surface on bond strength by suggesting a bar surface factor 599 of $k_{5}$ in the CSA-S806 equation and $k_{6}$ in the CSA-S6 equation. The ACI 440.1R equation 600 was developed based on concrete strength in the range of 28 to $45 \mathrm{MPa}$ [38]. Therefore, 601 it cannot be assumed to be accurate for predicting the bond strength of GFRP bars in 602 HSC. The Canadian code limitations regarding concrete strength $\left(\sqrt{f_{c}^{\prime}}\right.$ should not be more 
603 than 5 and $8 \mathrm{MPa}$ for CSA-S806 and CSA-S6, respectively) and concrete cover ( $\mathrm{d}_{\mathrm{cs}}$ is not 604 greater than $2.5 d_{b}$ ) lead to a constant value of the predicted bond strength for all 605 specimens as illustrated in Figure 18 (b) . The modification factor, $\alpha_{2}$, in the Japanese 606 equation was taken as 1 . According to the Japanese code limitation regarding the design 607 bond strength of concrete, the predicted bond strength is constant when the concrete 608 strength exceeds $57 \mathrm{MPa}$ as shown in Figure 18 (ㅁ). Because of the absence of 609 transverse reinforcement in the pull-out cubes, the effect of confinement considered by 610 the transverse reinforcement index, $k_{t r}$, in the CSA S6 equation and the transverse 611 reinforcement in the JSCE equation was neglected. The minimum value of the bond 612 strength in experimental results is higher than the bond strengths obtained from Canadian 613 and Japanese design codes, thus, the development length provided by these codes will 614 be over satisfactory.

615 Table $\underline{6}$. Comparison of test results of GFRP (type A) reinforced cubes with different code's 616 predictions

\begin{tabular}{|c|c|c|c|c|c|c|c|c|c|}
\hline $\begin{array}{l}\text { Specimen } \\
\text { label }\end{array}$ & $\begin{array}{c}\tau_{\text {exp }} \\
(\mathrm{MPa})\end{array}$ & $\begin{array}{c}\mathrm{ACl} \\
440.1 \mathrm{R} \\
\tau_{\text {pred }} \\
(\mathrm{MPa})\end{array}$ & $\frac{\tau_{\text {exp }}}{\tau_{\text {pred }}}$ & $\begin{array}{c}\text { CSA- } \\
\text { S806 } \\
\tau_{\text {pred }} \\
(\mathrm{MPa}) \\
\end{array}$ & $\frac{\tau_{\text {exp }}}{\tau_{\text {pred }}}$ & $\begin{array}{c}\text { CSA- } \\
\text { S6 } \\
\tau_{\text {pred }} \\
(\mathrm{MPa}) \\
\end{array}$ & $\frac{\tau_{\text {exp }}}{\tau_{\text {pred }}}$ & $\begin{array}{c}\text { JSCE } \\
1997 \\
\tau_{\text {pred }} \\
(\mathrm{MPa})\end{array}$ & $\frac{\tau_{\text {exp }}}{\tau_{\text {pred }}}$ \\
\hline$A-9.5-2.5 d$ & 20.55 & 34 & 0.60 & 4.11 & 5 & 7.07 & 2.91 & 5.33 & 3.85 \\
\hline$A-9.5-5 d$ & 20.08 & 18.91 & 1.06 & 4.11 & 4.89 & 7.07 & 2.84 & 5.33 & 3.77 \\
\hline$A-9.5-7.5 d$ & 19.76 & 13.88 & 1.42 & 4.11 & 4.81 & 7.07 & 2.79 & 5.33 & 3.71 \\
\hline$A-9.5-10 d$ & 19.27 & 11.36 & 1.70 & 4.11 & 4.69 & 7.07 & 2.73 & 5.33 & 3.61 \\
\hline$A-12.7-2.5 d$ & 19.79 & 34.07 & 0.58 & 4.11 & 4.82 & 7.07 & 2.80 & 5.33 & 3.71 \\
\hline$A-12.7-5 d$ & 16.13 & 18.95 & 0.85 & 4.11 & 3.92 & 7.07 & 2.28 & 5.33 & 3.02 \\
\hline$A-12.7-7.5 d$ & 16.71 & 13.90 & 1.20 & 4.11 & 4.07 & 7.07 & 2.36 & 5.33 & 3.13 \\
\hline$A-12.7-10 d$ & 16.05 & 11.38 & 1.41 & 4.11 & 3.91 & 7.07 & 2.27 & 5.33 & 3.01 \\
\hline$A-15.9-2.5 d$ & 19.42 & 34.76 & 0.56 & 4.11 & 4.73 & 7.07 & 2.75 & 5.33 & 3.64 \\
\hline$A-15.9-5 d$ & 18.70 & 19.33 & 0.97 & 4.11 & 4.55 & 7.07 & 2.64 & 5.33 & 3.51 \\
\hline A-15.9-7.5d & 16.32 & 14.23 & 1.15 & 4.11 & 3.97 & 7.07 & 2.31 & 5.33 & 3.06 \\
\hline$A-15.9-10 d$ & 14.82 & 11.65 & 1.27 & 4.11 & 3.61 & 7.07 & 2.10 & 5.33 & 2.78 \\
\hline \multicolumn{3}{|c|}{ Average } & 1.06 & & 4.41 & & 2.56 & & 3.40 \\
\hline \multicolumn{3}{|c|}{ COV \% } & 34.3 & & 10.9 & & 10.9 & & 10.9 \\
\hline
\end{tabular}


623 624 625 626 627
Note: $\tau_{\text {exp }}$ is the experimental bond strength; $\tau_{\text {pred }}$ is the predicted bond strength and COV is a Coefficient of variation.

Table 7. Comparison of test results of GFRP (type B) reinforced cubes with different code's predictions

\begin{tabular}{|c|c|c|c|c|c|c|c|c|c|}
\hline $\begin{array}{l}\text { Specimen } \\
\text { label }\end{array}$ & $\begin{array}{c}\tau_{\text {exp }} \\
(\mathrm{MPa})\end{array}$ & $\begin{array}{c}\mathrm{ACl} \\
440.1 \mathrm{R} \\
\tau_{\text {pred }} \\
(\mathrm{MPa})\end{array}$ & $\frac{\tau_{\text {exp }}}{\tau_{\text {pred }}}$ & $\begin{array}{c}\text { CSA- } \\
\text { S806 } \\
\tau_{\text {pred }} \\
(\mathrm{MPa}) \\
\end{array}$ & $\frac{\tau_{\text {exp }}}{\tau_{\text {pred }}}$ & $\begin{array}{c}\text { CSA- } \\
\text { S6 } \\
\tau_{\text {pred }} \\
\text { (MPa) } \\
\end{array}$ & $\frac{\tau_{\text {exp }}}{\tau_{\text {pred }}}$ & $\begin{array}{c}\text { JSCE } \\
1997 \\
\tau_{\text {pred }} \\
(\mathrm{MPa})\end{array}$ & $\frac{\tau_{\text {exp }}}{\tau_{\text {pred }}}$ \\
\hline B-9.5-2.5d & 28.91 & 31.42 & 0.92 & 4.32 & 6.69 & 7.07 & 4.09 & 5.33 & 5.42 \\
\hline B-9.5-5d & 25.51 & 16.89 & 1.51 & 4.32 & 5.91 & 7.07 & 3.61 & 5.33 & 4.78 \\
\hline B-9.5-7.5d & 22.15 & 12.40 & 1.79 & 4.32 & 5.13 & 7.07 & 3.13 & 5.33 & 4.15 \\
\hline B-9.5-10d & 19.05 & 10.15 & 1.88 & 4.32 & 4.41 & 7.07 & 2.69 & 5.33 & 3.57 \\
\hline B-12.7-2.5d & 28.26 & 30.78 & 0.92 & 4.32 & 6.54 & 7.07 & 4.00 & 5.33 & 5.30 \\
\hline$B-12.7-5 d$ & 23.21 & 17.12 & 1.36 & 4.32 & 5.37 & 7.07 & 3.28 & 5.33 & 4.35 \\
\hline B-12.7-7.5d & 19.83 & 12.38 & 1.60 & 4.32 & 4.59 & 7.07 & 2.80 & 5.33 & 3.72 \\
\hline B-12.7-10d & 18.18 & 10.14 & 1.79 & 4.32 & 4.21 & 7.07 & 2.57 & 5.33 & 3.41 \\
\hline B-15.9-2.5d & 27.77 & 30.34 & 0.92 & 4.32 & 6.43 & 7.07 & 3.93 & 5.33 & 5.21 \\
\hline B-15.9-5d & 21.52 & 16.87 & 1.28 & 4.32 & 4.98 & 7.07 & 3.04 & 5.33 & 4.04 \\
\hline B-15.9-7.5d & 19.23 & 12.38 & 1.55 & 4.32 & 4.45 & 7.07 & 2.72 & 5.33 & 3.61 \\
\hline B-15.9-10d & 18.93 & 10.14 & 1.87 & 4.32 & 4.38 & 7.07 & 2.68 & 5.33 & 3.55 \\
\hline \multicolumn{3}{|c|}{ Average } & 1.45 & & 5.26 & & 3.21 & & 4.26 \\
\hline \multicolumn{3}{|c|}{ COV \% } & 25.6 & & 17.4 & & 17.4 & & 17.4 \\
\hline
\end{tabular}

Note: $\tau_{\text {exp }}$ is the experimental bond strength; $\tau_{\text {pred }}$ is the predicted bond strength and COV is a Coefficient of variation. 
628

629

630

631

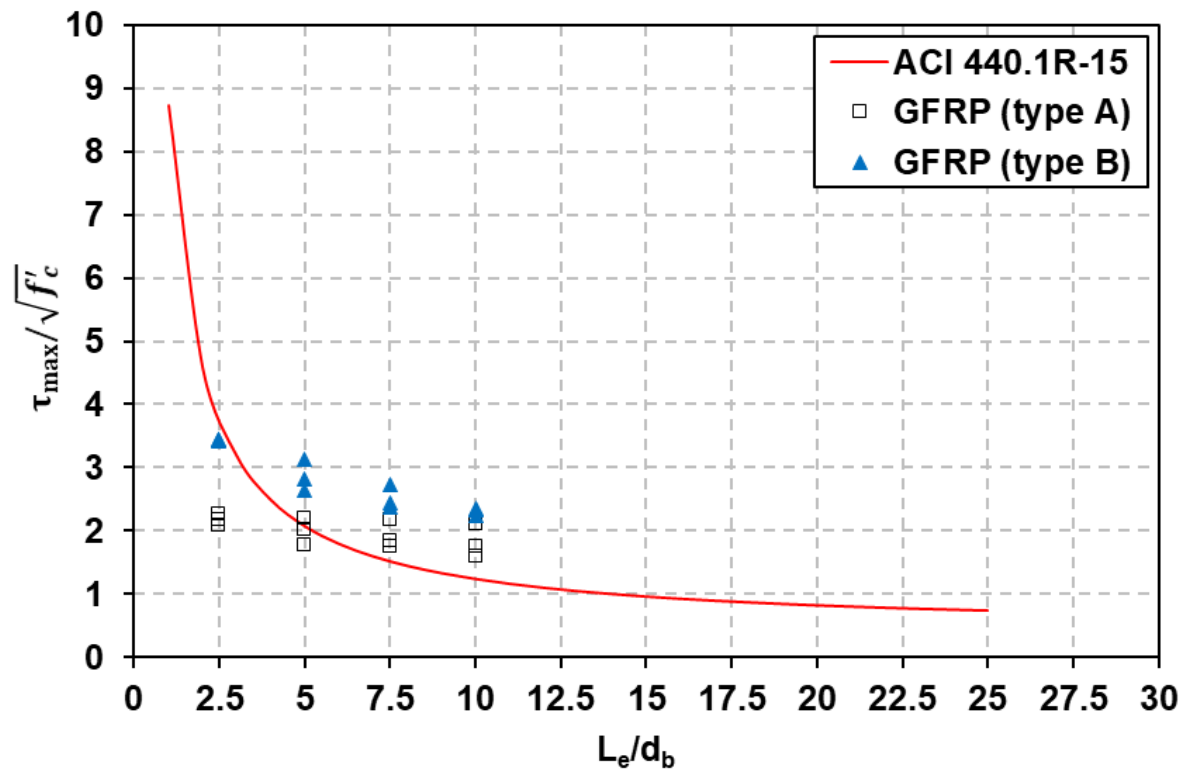

(a) Variation of normalized bond strength with embedment length

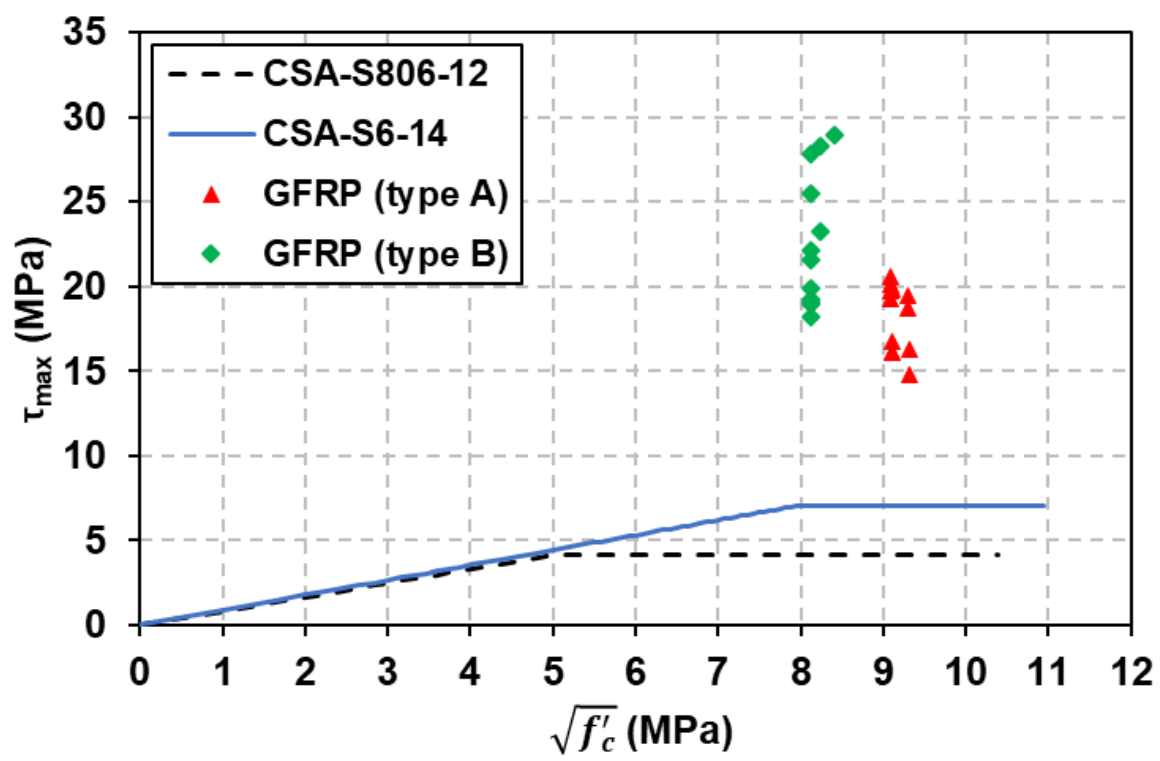

(b) Variation of bond strength vs. $\sqrt{f_{c}^{\prime}}$ 


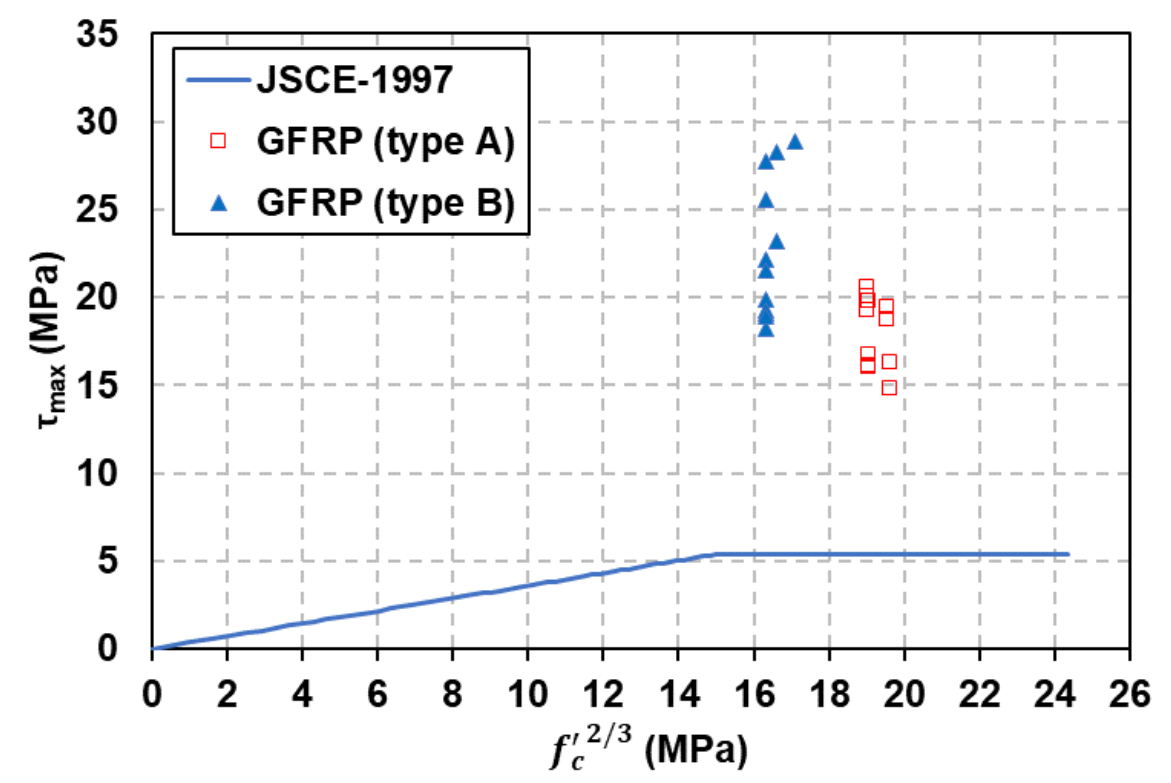

642

643

644

645

646

647

648

649

650

651

652

653

654

655

656

657

658

659

660

(c) Variation of bond strength vs. $f_{r}^{\prime 2 / 3}$ Figure 18. Comparison between experimental and different design code predicted bond strengths
for cubes

\section{Conclusions}

Test results of $84 \mathrm{HSC}$ pull-out specimens reinforced with GFRP and steel bars have been presented and discussed in this paper. The parameters investigated were diameter, embedment length and surface configuration of the reinforcing bars. The following conclusions are drawn:

- The majority of specimens failed by a pull-out mode. The bond failure of GFRP (HW-SC) reinforced specimens occurred within the interfaces of the resin-rich layer and fibres, while it occurred within the interfaces between the sand coated layer and the bar core in GFRP (SC) reinforced specimens. The shearing off of concrete $\underline{\text { between the steel ribs was responsible for a pull-out failure in control specimens. }}$

- GFRP (HW-SC) bars showed interfacial bond behaviour differing from that of GFRP $\underline{(S C)}$ bars. A helically wrapped with slightly sand coated surface produced a 
more ductile post peak response with high residual stresses owing to high friction forces between remaining undulations and concrete, similar to previous observations in the literature for normal-strength concrete. A sand coated surface produced a brittle failure because of the complete stripping of sand grains from the bar core, unlike the literature (a smoother softening curve in the case of normal strength concrete).

- Overall, the bond strength of both GFRP types increased with reducing the embedment length and bar diameter.

- In general, the reduction rate of bond strength of both GFRP types with increasing the bar diameter and the embedment length was reduced in the case of highstrength concrete.

- The sand coated surface offered a bond strength higher than that offered by the helically wrapped with slightly sand coated surface for a given concrete strength, but the corresponding slip for GFRP (SC) bars was less than that for GFRP (HWSC) bars. to other codes.

- Both Canadian and Japanese codes are overly safe. Therefore, modifications to these codes are necessary for a more accurate prediction of bond strength of GFRP bars embedded in HSC. 


\section{Acknowledgement}

685 The first Author would like to acknowledge to the financial support of Higher Education of

686 Libya (293/2013). The authors are also gratefully to PULTRALL \& V.ROD for providing 687 the GFRP (SC) bars, and Hughes brother's manufacturer and Fortius, Belgium Vendor for 688 providing the ASLAN 100 GFRP (HW-SC) bars.

689

690

691

692

693

694

695

696

697

698

699

700

701

702

703 


\section{References}

705 1. Achillides, Z. and K. Pilakoutas, Bond behaviour of fibre reinforced polymer bars under direct pullout conditions. Journal of Composites for Construction, 2004. 8(2): p. 173-181.

2. Okelo, R. and R.L. Yuan, Bond strength of fibre reinforced polymer rebars in normal strength concrete. Journal of composites for construction, 2005. 9(3): p. 203-213.

3. Tastani, S. and S. Pantazopoulou, Bond of GFRP bars in concrete: experimental study and analytical interpretation. Journal of Composites for Construction, 2006. 10(5): p. 381-391.

4. Hao, Q.-d., Y.-I. Wang, Z.-C. Zhang, and J.-p. Ou, Bond strength improvement of GFRP rebars with different rib geometries. Journal of Zhejiang University SCIENCE A, 2007. 8(9): p. 1356-1365.

5. Baena, M., L. Torres, A. Turon, and C. Barris, Experimental study of bond behaviour between concrete and FRP bars using a pull-out test. Composites Part B: Engineering, 2009. 40(8): p. 784-797.

6. Hao, Q., Y. Wang, Z. He, and J. Ou, Bond strength of glass fibre reinforced polymer ribbed rebars in normal strength concrete. Construction and Building materials, 2009. 23(2): p. 865-871.

7. El Refai, A., M.-A. Ammar, and R. Masmoudi, Bond performance of basalt fibrereinforced polymer bars to concrete. Journal of Composites for Construction, 2014. 19(3): p. 04014050.

8. Xue, W., Q. Zheng, Y. Yang, and Z. Fang, Bond behaviour of sand-coated deformed glass fibre reinforced polymer rebars. Journal of Reinforced Plastics and Composites, 2014. 33(10): p. 895-910.

9. Benmokrane, B., O. Chaallal, and R. Masmoudi, Glass fibre reinforced plastic (GFRP) rebars for concrete structures. Construction and Building Materials, 1995. 9(6): p. 353-364.

10. Lee, J.-Y., T.-Y. Kim, T.-J. Kim, C.-K. Yi, J.-S. Park, Y.-C. You, and Y.-H. Park, Interfacial bond strength of glass fibre reinforced polymer bars in high-strength concrete. Composites Part B: Engineering, 2008. 39(2): p. 258-270.

11. Davalos, J.F., Y. Chen, and I. Ray, Effect of FRP bar degradation on interface bond with high strength concrete. Cement and Concrete Composites, 2008. 30(8): p. 722-730.

12. Lee, J.Y., C.K. Yi, Y.G. Cheong, and B.I. Kim, Bond stress-slip behaviour of two common GFRP rebar types with pullout failure. Magazine of Concrete Research, 2012. 64(7): p. 575-591.

13. Hossain, K.M.A., D. Ametrano, and M. Lachemi, Bond Strength of Standard and High-Modulus GFRP Bars in High-Strength Concrete. Journal of Materials in Civil Engineering, 2014. 26(3): p. 449-456. 
14. Tekle, B.H., A. Khennane, and O. Kayali, Bond Properties of Sand-Coated GFRP Bars with Fly Ash-Based Geopolymer Concrete. Journal of Composites for Construction, 2016. 20(5): p. 1-13.

15. Lee, J.-Y., A.-R. Lim, J. Kim, and J. Kim, Bond behaviour of GFRP bars in highstrength concrete: bar diameter effect. Magazine of Concrete Research, 2017. 69(11): p. 541-554.

16. Tighiouart, B., B. Benmokrane, and D. Gao, Investigation of bond in concrete member with fibre reinforced polymer (FRP) bars. Construction and Building Materials, 1998. 12(8): p. 453-462.

17. Chaallal, O. and B. Benmokrane, Pullout and bond of glass-fibre rods embedded in concrete and cement grout. Materials and structures, 1993. 26(3): p. 167-175.

18. Veljkovic, A., V. Carvelli, M.M. Haffke, and M. Pahn, Concrete cover effect on the bond of GFRP bar and concrete under static loading. Composites Part B: Engineering, 2017. 124: p. 40-53.

19. Harajli, M. and M. Abouniaj, Bond performance of GFRP bars in tension: Experimental evaluation and assessment of $\mathrm{ACl} 440$ guidelines. Journal of Composites for Construction, 2010. 14(6): p. 659-668.

20. Esfahani, M.R., M. Rakhshanimehr, and S.R. Mousavi, Bond Strength of LapSpliced GFRP Bars in Concrete Beams. Journal of Composites for Construction, 2013. 17(3): p. 314-323.

21. ACl-440.1R, Guide for the design and construction of concrete reinforced with FRP bars. 2015, ACl Committee 440: Farmington Hills, M1.

22. CAN/CSA-S806, Design and construction of building structures with fibrereinforced polymers. 2012, Canadian Standards Association: Mississauga, Ontario, Canada.

23. CAN/CSA-S6, Canadian Highway Bridge Design Code. 2014, Canadian Standard Association.

24. JSCE, Recommendation for Design and Construction of Concrete Structures using Continuous Fibre Reinforcing Materials. 1997, Research Committee FibreReinforcing Materials: Tokyo, Japan.

25. ACl-440.3R, Guide Test Methods for Fibre-Reinforced Polymers (FRPs) for Reinforcing or Strengthening Concrete Structures. 2012, ACl Committee 440: Farmington Hills, M1.

26. ASTM-D7205/D7205M-06, Standard test method for tensile properties of fibre reinforced polymer matrix composite bars. 2006, ASTM International: West Conshohocken, United States. p. 13.

27. ASTM-A706/A706M-09b, Standard Specification for Low-Alloy Steel Deformed and Plain Bars for Concrete Reinforcement. 2009, ASTM International: West Conshohocken, United States. p. 6. 
28. Vint, L. and S. Sheikh, Investigation of Bond Properties of Alternate Anchorage Schemes for Glass Fibre-Reinforced Polymer Bars. ACI Structural Journal, 2015. 112(1): p. 59.

29. Antonietta Aiello, M., M. Leone, and M. Pecce, Bond performances of FRP rebarsreinforced concrete. Journal of materials in civil engineering, 2007. 19(3): p. 205213.

30. Arias, J.P.M., A. Vazquez, and M.M. Escobar, Use of sand coating to improve bonding between GFRP bars and concrete. Journal of composite materials, 2012. 46(18): p. 2271-2278.

31. Pepe, M., H. Mazaheripour, J. Barros, J. Sena-Cruz, and E. Martinelli, Numerical calibration of bond law for GFRP bars embedded in steel fibre-reinforced selfcompacting concrete. Composites Part B: Engineering, 2013. 50: p. 403-412.

32. Nanni, A., M. Al-Zaharani, S. Al-Dulaijan, C. Bakis, and I. Boothby. bond of FRP reinforcement to concrete-experimental results. in Non-Metallic (FRP) Reinforcement for Concrete Structures: Proceedings of the Second International RILEM Symposium. 1995. CRC Press.

33. Benmokrane, B., B. Tighiouart, and O. Chaallal, Bond strength and load distribution of composite GFRP reinforcing bars in concrete. ACI Materials Journal, 1996. 93(3): p. 246-252.

34. Cosenza, E., G. Manfredi, and R. Realfonzo, Behaviour and modeling of bond of FRP rebars to concrete. Journal of composites for construction, 1997. 1(2): p. 4051.

35. Achillides, Z., Bond behaviour of FRP bars in concrete, in Dept. of Civil and Structural Engineering. 1998, University of Sheffield: Sheffield, U.K.

36. Tepfers, R., Bond clause proposals for FRP bars/rods in concrete based on CEB/FIP Model Code 90. Part 1: Design bond stress for FRP reinforcing bars. Structural concrete, 2006. 7(2): p. 47-55.

37. Xue, W., X. Wang, and S. Zhang, Bond properties of high-strength carbon fibrereinforced polymer strands. ACI Materials Journal, 2008. 105(1): p. 11-19.

38. Wambeke, B.W. and C.K. Shield, Development length of glass fibre-reinforced polymer bars in concrete. ACI Structural Journal, 2006. 103(1): p. 11-17.

\section{Abbreviations}

GFRP Glass Fibre Reinforced Polymers

HW-SC Helical Wrapping with slightly Sand Coating

SC Sand Coating

CFRM Continuous Fibre Reinforcing Materials

NSC Normal Strength Concrete

HSC High Strength Concrete 
$821 \mathrm{ACl} \quad$ American Concrete Institute

822 ASTM American Society for Testing and Materials

823 JSCE Japanese Society of Civil Engineers

824 CSA Canadian Standards Association

825 COV Coefficient of Variation

826 LVDT Linear Variable Displacement Transducer

827 PO Pull-out

828 SP Splitting

829 Y Yielding

830

831 Notations

$832 \quad d_{b} \quad$ Bar diameter

$833 L_{e} \quad$ Embedment length

$834 L_{d b} \quad$ Development length

$835 L_{a} \quad$ Length from the LVDTs support point to the top surface of the bonded bar

$836 A_{b} \quad$ Cross sectional area of bar

$837 A_{t} \quad$ Cross-sectional area of transverse reinforcement

$838 f_{c}^{\prime} \quad$ Cylinder compressive strength of concrete

$839 f_{c u} \quad$ Cube compressive strength of concrete

$840 f_{t} \quad$ Tensile strength of concrete

$841 f_{c r} \quad$ Cracking strength of concrete

$842 E_{f r p} \quad$ Elastic modulus of FRP rebar

$843 \quad E_{S} \quad$ Elastic modulus of steel rebar

$844 \quad \alpha_{1} \quad$ Confinement modification factor

$845 \quad \alpha_{2} \quad$ Modification factor for bond strength

$846 f_{\text {bod }}$ Design bond strength of concrete

$847 \quad E_{t} \quad$ Young's modulus of elasticity for the transverse reinforcement

$848 f_{y t} \quad$ Yield stress in transverse reinforcement

$849 \quad k_{1} \quad$ Top bar modification factor

$850 \quad k_{2} \quad$ Concrete density factor

$851 \quad k_{3} \quad$ Bar size factor

$852 \quad k_{4} \quad$ Bar fibre factor

$853 \quad k_{5} \quad$ Surface profile factor

$854 \quad k_{6} \quad$ Bar surface factor

$855 k_{t r} \quad$ Transverse reinforcement index

856 C The lesser of the concrete cover to the centre of the bar or one-half of the centre-

857 to-centre spacing of the bars being developed

$858 d_{c s} \quad$ The smaller of the distance from the closest concrete surface to the centre of the 859 bar or two-thirds of the centre to centre spacing of the bars 
$860 \mathrm{~S} \quad$ Maximum spacing centre to centre of transverse bars within $l_{d b}$

$861 \mathrm{n} \quad$ Number of bars being developed along the potential plane of bond splitting

$862 \tau_{\max }$ Peak bond stress

$863 \tau \quad$ Bond stress

$864 \tau_{\text {avg }}$ Average bond strength

$865 \tau_{\text {pred }}$ Predicted bond strength

$866 \tau_{\text {exp }} \quad$ Experimental bond strength

867 F Applied tensile load

$868 \quad \mathrm{~F}_{\max }$ Failure load

$869 s_{l e} \quad$ Loaded end slip at the peak bond stress

$870 s_{u l} \quad$ Unloaded end slip at the peak bond stress

$871 s_{e} \quad$ Elongation of the bar

$872 s_{\text {total }}$ LVDT measurement at the loaded end

$873 s_{l e, m} \quad$ Average loaded end slip at the peak bond stress

$874 s_{u l, m} \quad$ Average unloaded end slip at the peak bond stress 